\title{
Dynamic exergoeconomic analysis of a heat pump system used for ancillary services in an integrated energy system
}

\author{
Meesenburg, Wiebke; Ommen, Torben; Elmegaard, Brian
}

Published in:

Energy

Link to article, DOI:

10.1016/j.energy.2018.03.093

Publication date:

2018

Document Version

Peer reviewed version

Link back to DTU Orbit

Citation $(A P A)$ :

Meesenburg, W., Ommen, T., \& Elmegaard, B. (2018). Dynamic exergoeconomic analysis of a heat pump system used for ancillary services in an integrated energy system. Energy, 152, 154-165.

https://doi.org/10.1016/j.energy.2018.03.093

\section{General rights}

Copyright and moral rights for the publications made accessible in the public portal are retained by the authors and/or other copyright owners and it is a condition of accessing publications that users recognise and abide by the legal requirements associated with these rights.

- Users may download and print one copy of any publication from the public portal for the purpose of private study or research.

- You may not further distribute the material or use it for any profit-making activity or commercial gain

- You may freely distribute the URL identifying the publication in the public portal

If you believe that this document breaches copyright please contact us providing details, and we will remove access to the work immediately and investigate your claim. 


\section{Accepted Manuscript}

Dynamic exergoeconomic analysis of a heat pump system used for ancillary services in an integrated energy system

Wiebke Meesenburg, Torben Ommen, Brian Elmegaard

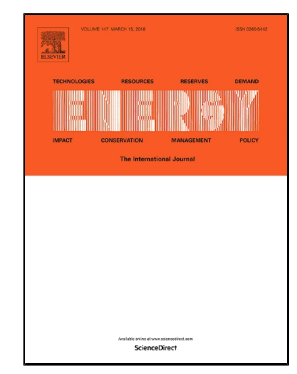

PII:

S0360-5442(18)30502-4

DOI:

10.1016/j.energy.2018.03.093

Reference:

EGY 12551

To appear in:

Energy

Received Date:

20 November 2017

Revised Date:

09 March 2018

Accepted Date:

17 March 2018

Please cite this article as: Wiebke Meesenburg, Torben Ommen, Brian Elmegaard, Dynamic exergoeconomic analysis of a heat pump system used for ancillary services in an integrated energy system, Energy (2018), doi: 10.1016/j.energy.2018.03.093

This is a PDF file of an unedited manuscript that has been accepted for publication. As a service to our customers we are providing this early version of the manuscript. The manuscript will undergo copyediting, typesetting, and review of the resulting proof before it is published in its final form. Please note that during the production process errors may be discovered which could affect the content, and all legal disclaimers that apply to the journal pertain. 


\title{
Dynamic exergoeconomic analysis of a heat pump system used for ancillary services in an integrated energy system \\ Wiebke Meesenburg ${ }^{* 1}$, Torben Ommen ${ }^{1}$, Brian Elmegaard ${ }^{1}$
}

\author{
${ }^{1}$ Department of Mechanical Engineering, Technical University of Denmark, Lyngby, Denmark
}

Keywords: Dynamic exergoeconomic analysis, integrated energy systems, heat pump, flexibility, ancillary services

1

2

\section{Abstract}

The integration of different energy sectors, such as the electricity and heating sector, is an effective way to integrate large shares of renewable energy into the energy system. Heat pumps allow efficient heat production based on electricity. As such, they may be used to provide two different services - the generation of heat and the provision of demand flexibility as ancillary services for the power system. The paper presents a method to assess the impact of providing demand flexibility on the performance of the conversion system based on a dynamic exergoeconomic analysis. A way to allocate the cost of heat and flexibility products based on the difference in exergy destruction was proposed. The method was applied to a case of a groundwater-source heat pump system supplying a district heating island system. It was found that providing demand flexibility causes higher exergy destruction, mainly due to heat losses during storage and the need to reheat the fluid using an electric heater. The major part of the additional exergy destruction was not related to heat pump regulation. When providing flexibility the overall cost of the system increased and according to the proposed allocation, demand flexibility accounted for $12 \%$ of the overall cost.

\footnotetext{
${ }^{*}$ Corresponding author: wmeese@mek.dtu.dk
} 


\section{Introduction}

17 The future Danish energy system will be characterized by high shares of transient renewable power

18 production [1]. One of the main challenges imposed by this is to design future energy systems to be able to balance high shares of fluctuating power and to achieve an efficient use of the energy available. This challenge may be met by integrating the power, heating and mobility sectors. Synergies can be exploited, and it is expected that it will be possible to allocate higher shares of renewable energy, increase the overall energy efficiency of the system and help to ensure a reliable and resilient energy system [2].

The heating sector can absorb large amounts of electricity and additionally offers the possibility to store the energy as heat in heat storages, buildings and district heating systems [3]. Different technologies are available to couple the heating and electricity sector by converting one energy form into another, such as heat pumps and electric heaters. Mathiesen and Lund [4] found that large scale heat pumps are especially promising to efficiently integrate large amounts of renewable energy into the system. However, the ability and limitations of large heat pumps to provide demand flexibility need further investigation [5].

In this study, we focus on the integration between the heating and the power system by analyzing a heat pump system supplying a district heating island system. Further, the system acts as a controllable load in the power system, i.e. the heat pump electricity consumption changes according to signals from the power system operator [6]. Previous studies showed that the integration of the electricity and the heating sectors offers the possibility to decouple electricity supply and demand constraints and can provide balancing service to the power sector [7]. Stinner et al. [8] confirmed that balancing services from lower voltage levels are necessary in energy systems with a high share of renewables to balance the distribution and transmission grids. Further, controlling the load of heat pumps flexibly can reduce 
$\mathrm{CO}_{2}$ emissions and lower $\mathrm{CO}_{2}$ abatement cost, while the overall electricity consumption may increase

40

41

42

43

44

45

46

47

[9].

The considered conversion system provides two different products - the heat supplied to the district heating grid and the ancillary service to the electricity grid. This has several consequences for the operation of the heat pump. Firstly, the operation strategy has to take the demand of heat and power regulation into consideration. Secondly, the ability to provide flexibility comes at the cost of increased investment cost for a larger conversion system. Thirdly, the flexible operation leads to additional losses in the conversion system. The three consequences open for investigations of the valuation of the different products and the additional cost of flexible operation.

Ulbig \& Andersson define the operational flexibility of a power system as the technical ability of a power system to modulate the power feed-in or load over time [10]. Extending this definition to integrated energy systems, we propose to define flexibility as the technical ability of a energy conversion system to adapt the power feed-in, load or conversion into other forms of energy in order to optimize security of supply, cost and/or environmental impact of the overall energy system.

Different studies have been carried out in an effort to determine the value of flexibility provided by heat pumps and electric heaters. Three general approaches were identified.

The first approach is to define an average flexibility value by considering the differences between supply and demand [7], [11], [12]. This approach is based on the idea that the unit that adapts to the state of the system, and thus decreases the difference between supply and demand, provides a balancing service to the system.

The second approach takes the specifications regarding ramping rates and capacities of the different components into consideration. In this way it evaluates the actual potential of a component to react to 
61 regulation needs of the system at a certain point in time with respect to the current state of component

62 operation [10-12].

63 The third approach is to evaluate the flexibility of a unit by evaluating the cost effectiveness of an

64 increase of flexibility. Blarke \& Lund [15] defined the cost effectiveness of the storage or relocation

65 option as the shadow cost associated with increased flexibility of a certain unit. Meibom et al. [16]

66 propose to evaluate the impact of heat pumps and electric boilers according to their influence on the

67 price of regulating power.

68 All these approaches value flexibility according to the benefit of the power system or of the overall

69 energy system. However, it is important to assess which cost is associated with providing ancillary

70 services for the heat pump system operator, as this is valuable information when deciding on the

71 operation strategy and the system design. The analysis of the actual changes induced to the conversion

72 system and the associated costs requires a more detailed method than suggested by the above

73 references.

74 In the present study, the performance of a conversion system was analyzed using an exergoeconomic

75 approach. A dynamic model of the system was simulated and a dynamic exergoeconomic analysis was

76 conducted in order to reveal the exergy destruction connected to the flexible operation of the system

77 and where and when it occurs. The method of exergoeconomic analysis is a combination of an exergy

78 analysis and economic principles and is used to obtain information about how to design and operate

79 energy conversion systems in a cost-effective way [17]. It enables the allocation of cost to multiple

80 products of any energy conversion plant based on a framework that consistently connects economics

81 and thermodynamics. Usually, an exergoeconomic analysis is conducted assuming steady state

82 processes. Sayadi et al. [18] conducted a dynamic exergy and exergoeconomic analysis for a building 
envelope. Sangi et al. [19] presented an approach, to conduct a quasi-dynamic exergoeconomic analysis by analyzing the result of each time step for a dynamic simulation of a building heating system.

In this paper, we used a dynamic exergoeconomic analysis to assess the system performance. The method is extended by the definition of exergy fuel and exergy product for the stratified storage tank and an approach to allocate the cost to both products of the system - heat and demand flexibility. In section 2 we describe the method, including a description of the case study, the mathematical model, exergy and exergoeconomic analysis. Section 3 presents the results found for the case study and section 4 discusses the results and the method that was used. Finally, in section 5 the conclusions are presented.

\section{Method}

The paper presents an approach to use dynamic exergoeconomic analysis to assess the performance of a conversion unit in an integrated energy system. Further, we propose a way to allocate the cost between heat and demand flexibility. The method is applied to a case presented in the following.

\subsection{Case study}

The case studied was a district heating island system that was designed for the Ocean Quay cruise ship terminal in Copenhagen. The system was designed to supply three terminal buildings and a large warehouse with heat for space heating and domestic hot water. The heat pump replaced the formerly implemented oil burners and has a nominal capacity of $800 \mathrm{~kW}$. Figure 1 shows a sketch of the described system and all water and electricity flows in the system. The heat source for the heat pump was groundwater delivered by the groundwater (GW) pump. Further, the system comprised a stratified storage tank of $120 \mathrm{~m}^{3}$, a district heating (DH) pump and two electric boilers of $100 \mathrm{~kW}$ each. The heat demand, including distribution losses, was lumped into a heat demand model and it was assumed that 
105 the heat pump system should supply a constant temperature of $70^{\circ} \mathrm{C}$ into the $\mathrm{DH}$ grid (Stream 8 in

106 Figure 1). Table 1 summarizes the capacity of the components used in the assessed case.

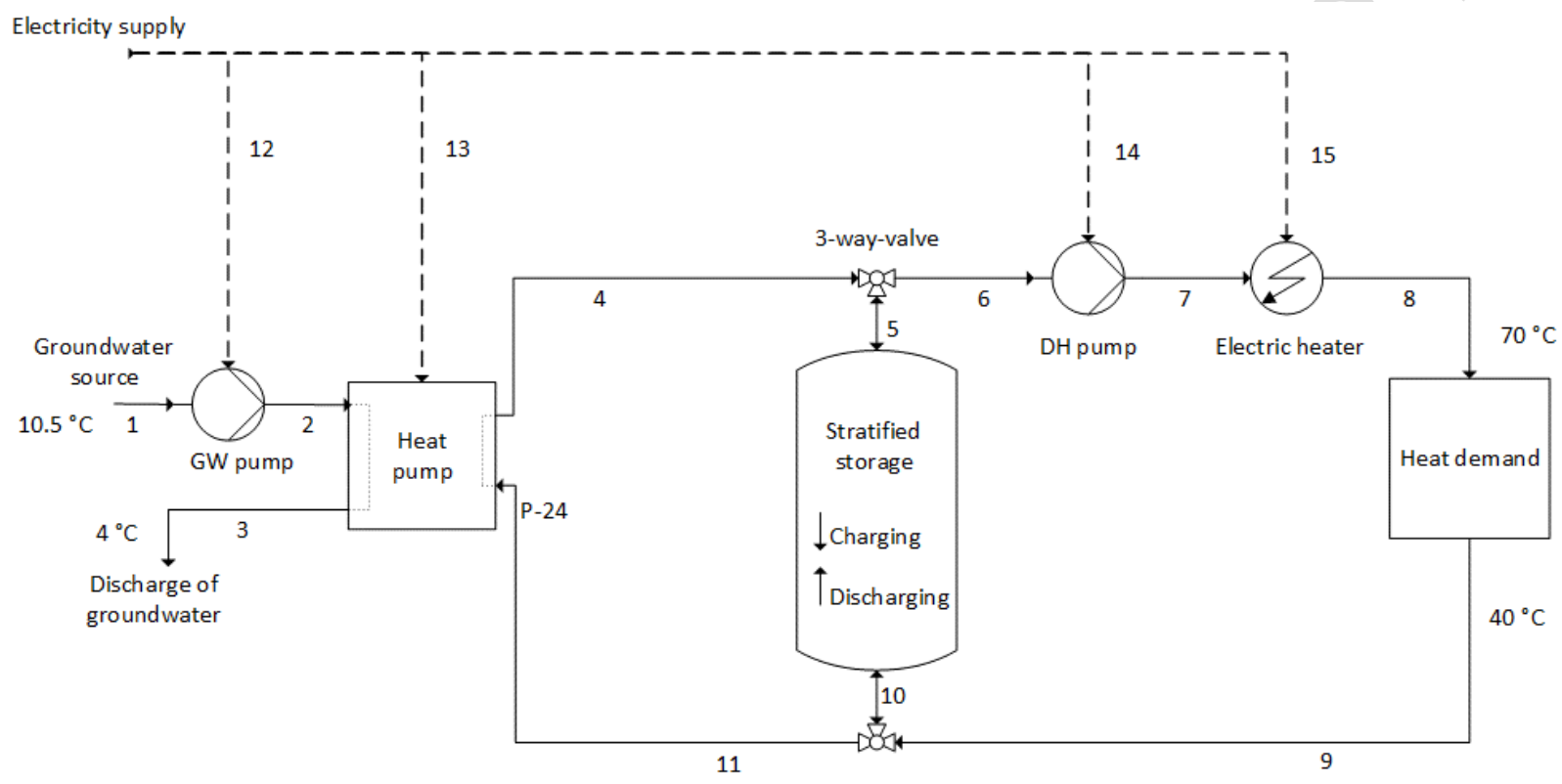

Figure 1 Sketch of the considered heat pump system in, Copenhagen, solid lines - water, dashed lines - electricity

Table 1 Specification of units in the considered system

\begin{tabular}{lr}
\hline Unit & \multicolumn{1}{c}{ Capacity } \\
\hline Heat pump minimum heating capacity & $150 \mathrm{~kW}$ \\
Heat pump nominal heating capacity & $800 \mathrm{~kW}$ \\
Electric boiler capacity & $2 \cdot 100 \mathrm{~kW}$ \\
District heating pump design flow & $2 \cdot 16.7 \frac{\mathrm{kg}}{\mathrm{s}}$ \\
Groundwater pump design flow & $2 \cdot 44.3 \frac{\mathrm{kg}}{\mathrm{s}}$ \\
Stratified Storage tank & $120 \mathrm{~m}^{3}$ \\
\hline
\end{tabular}


107 To compare the results on an energy basis we defined the seasonal heat pump COP and the seasonal

108 system coefficient of performance (SCOP) as

$$
\begin{gathered}
\mathrm{COP}_{\text {season }}=\frac{Q_{\text {heat }}}{W_{\mathrm{HP}}} \\
\mathrm{SCOP}_{\text {season }}=\frac{Q_{\text {heat }}}{\sum_{k} W_{\mathrm{k}}}
\end{gathered}
$$

109 where $Q_{\text {heat }}$ denotes the annual amount of heat delivered into the $\mathrm{DH}$ network, $W_{k}$ is the annual

110 amount of electric energy supplied to component $k$ and accordingly $W_{\mathrm{HP}}$ is the annual amount of

111 electric energy supplied to the heat pump.. In the sum all electrical components, i.e. the heat pump, the

112 electric heater, the groundwater pump and the DH pump were considered.

1132.2 Model

114 The model was formulated in Modelica [20] and implemented in Dymola [21]. It contained seven main 115 component models representing a heat pump, an electric boiler, a stratified storage tank, two pumps, a

116 lumped heat demand model, two three-way-valves and a central control unit. Models for the heat

117 demand, the heat pump, the control unit and stratified storage tank are further described below. All

118 models were based on energy, mass and impulse balance equations. When not indicated differently,

119 pressure losses were neglected. The pump model was adapted from an existing model from the TIL

120 library [22]. The pump efficiency was implemented as a quadratic function, obtained from

121 manufacturer's data $[23,24]$.

122 Heat demand model

123 The heat demand model was a simplified model of the demand side of the system. It included the

124 accumulated demand of all buildings and the heat losses in the distribution system. The demand was

125 measured demand data of the system on hourly basis for the year 2012 [25]. In practice, the heat 
126 demand would be forecasted and the operation schedule of the day ahead would be optimized.

127 However, for the current study a simplified approach was chosen. Based on the demand data, the 128 required mass flow for each time step was calculated which was used to control the district heating 129 pump supplying the network. It was assumed that the building substations are designed to cool the 130 district heating water to a constant return temperature of $40^{\circ} \mathrm{C}$ (Stream 9 Figure 1 ). The actually 131 supplied heat was calculated from an energy balance in the model. The system pressure loss was 132 estimated to be at 3 bar, independently of the flow.

133 Heat pump model

134 The heat pump was a two stage ammonia heat pump with open intercooler. It was equipped with a

135 piston compressor, which was controlled via a variable frequency drive. Brackish groundwater at $10.5^{\circ} \mathrm{C}$

136 was the heat source. It was assumed that the groundwater can be cooled to $4{ }^{\circ} \mathrm{C}$ before being

137 discharged into the sea.

138 A dynamic energy balance for the heat pump was used to describe the model.

$$
\frac{d Q_{H P}}{d t}=\dot{Q}_{e v a}+\dot{W}_{H P}+\dot{Q}_{c o n}
$$

139 The term $\mathrm{dQ}_{\mathrm{HP}} / \mathrm{dt}$ represents the changed heat flow due to inertia in the heat pump. $\dot{Q}_{\mathrm{eva}}$ is the heat

140 flow in the evaporator, $\dot{W}_{\mathrm{HP}}$ is the power uptake of the compressor and $\dot{Q}_{\text {con }}$ represent the condenser 141 heat load. 


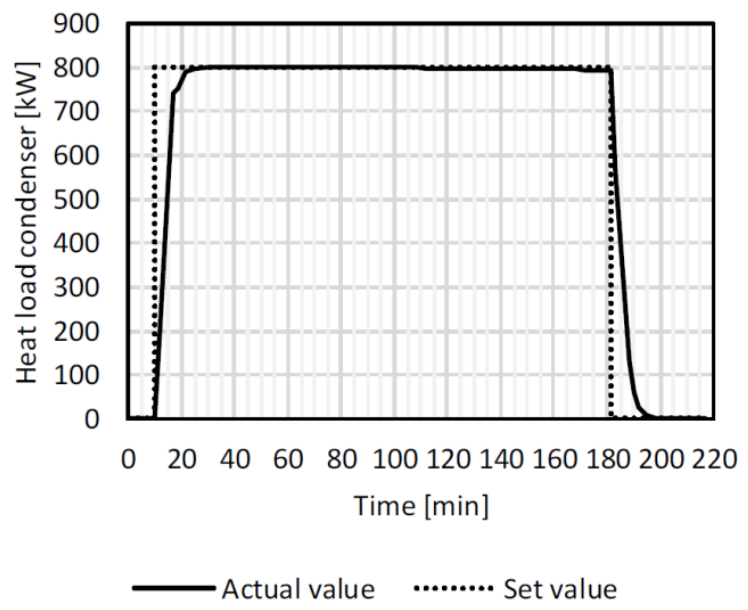

Figure 2 Steady state set value and actual value of condenser heat load for start-up and shut-down

142 The heat pump is implemented as a black box. Thus, a function for the actual heat output from the

143 condenser during load changes was implemented to represent the dynamic start-up and load changing 144 characteristics of the heat pump. Full heat production is not available during start-up compared to an 145 theoretic instantaneous start-up, and heat will still still be rejected after shut-off of the compressor

146 (Figure 2). It was assumed that the dynamic heat load at the condenser follows a first order

147 characteristic, which was included as function for the actual heat load $\dot{Q}_{\text {con }}$ into the model.

$$
\frac{d \dot{Q}_{\mathrm{con}}}{d t}=\left\{\begin{array}{cc}
k_{1} \cdot\left(\dot{Q}_{\mathrm{con}, \mathrm{ss}}-\dot{Q}_{\mathrm{con}}\right) & \text { for }\left(\dot{Q}_{\mathrm{con}, \mathrm{ss}}-\dot{Q}_{\mathrm{con}}\right)>0(\mathrm{ramp}-\mathrm{up}) \\
k_{2} \cdot\left(\dot{Q}_{\mathrm{con}, \mathrm{ss}}-\dot{Q}_{\mathrm{con}}\right) & \text { for }\left(\dot{Q}_{\mathrm{con}, \mathrm{ss}}-\dot{Q}_{\mathrm{con}}\right) \leq 0(\mathrm{ramp}-\mathrm{down})
\end{array}\right.
$$

148 The parameters $k_{1}=0.0016$ and $k_{2}=0.0018$ were chosen to represent a start-up time of 15 minutes

149 and a shut-down time of 20 minutes. The term $\dot{Q}_{\text {con,ss }}$ represents the condenser heat load in steady

150 state, which was calculated from the coefficient of performance (COP) in steady state. It was assumed

151 that COP in steady-state depends solely on the sink and source temperatures and a given exergy

152 efficiency $\epsilon_{s S}[26]$.

$$
\mathrm{COP}_{\mathrm{ss}}=\left(1-\frac{T_{m, \text { source }}}{T_{0}} *\left(\frac{1}{\epsilon_{\mathrm{ss}}} *\left(\frac{T_{0}}{T_{m, \text { sink }}}-1\right)+1\right)\right)^{-1}
$$




$$
\begin{gathered}
T_{m, i}=\frac{T_{\text {out }, i}-T_{\mathrm{in}, i}}{\ln \left(\frac{T_{\mathrm{out}, i}}{T_{\mathrm{in}, i}}\right)} \\
\dot{W}_{\mathrm{el}, \mathrm{HP}}=\frac{\dot{Q}_{\mathrm{con}, \mathrm{ss}}}{\mathrm{COP}_{s s}}
\end{gathered}
$$

$153 T_{m, i}$ is the logarithmic mean temperature and $T_{0}$ is the reference state temperature. $\epsilon_{\mathrm{sS}}$ represents the 154 steady-state exergy efficiency of the heat pump. It was assumed to have a constant value of 0.5. The 155 part-load COP of a frequency controlled heat pump would typically increase for decreasing load, 156 reaching a maximum at approx. 50 \%[27]. However, we assumed constant part load efficiency.

157 The resulting actual COP was calculated from the condenser heat load and the power uptake.

$$
\mathrm{COP}=\frac{\dot{Q}_{\mathrm{con}}}{\dot{W}_{\mathrm{HP}}}
$$

158 The model further included energy, mass and impulse balance (no pressure loss) equations for the 159 evaporator and the condenser. The heat pump was controlled according to the desired heat output at 160 the condenser using an external control unit.

161 Control unit

162 The described system was controlled using a central control unit, which contained the algorithm 163 according to which the heat pump, the three-way-valve, the pumps and the electric heater were 164 controlled. Via the three-way-valve at the top of the stratified storage tank the charging and discharging 165 of the tank was controlled, by setting a value for the ratio between the flow into the storage and the 166 flow from the HP. The pumps were controlled to deliver the necessary mass flow to the heat demand 167 model and the heat pump, respectively. The electric heater heated the $\mathrm{DH}$ supply flow to $70{ }^{\circ} \mathrm{C}$ if the 168 temperature supplied was lower. 
169

170

171

172

173

174

175

176

177

178

179

180

181

182

183

184

185

186

187

188

189

190

191

192

The operation of the heat pump was based on a simple, heuristic approach, which does not utilize variations in the electricity price, but is only based on the heat demand, the state of the storage and a regulation signal. This approach was chosen to focus on the effect of the provision of ancillary services for the electricity system. The algorithm changed the mode of operation of the system according to upand down regulation signals, which were taken from data of hourly realized up- and down-regulation from the Transmission System Operator Energinet.dk's market data from 2012 [28]. The model does not include the prices for regulating power, but aims at quantifying the true cost of providing this. The results may be compared to the actual prices in the regulating market.

The up- and down regulation signals from Energinet are based on the generation side, i.e. an upregulation signal means that the current demand is too high. The heat pump would react to this by reducing the power uptake. Accordingly, a down regulation signal would cause the heat pump to switch to full load. When the storage level and the current heat demand allowed for variation of the heat pump load, the heat pump was ramped up to full load in case of a down-regulation signal and shut-off for an up-regulation. This was done using a PI-controller $(k=0.08, \tau=50 \mathrm{~s})$ where the desired heat output was the set value, the actual heat load was the input and the power uptake of the compressor was the output signal. In practice, the load of the heat pump could be increased or reduced to another value than full load or no production. However, the considered heat pump is small in terms of its electricity regulation ability and would have to be aggregated to actually act on the regulation market. Therefore, we chose to only consider the maximum provision of regulation power. Figure 3 shows a flow diagram of the control algorithm for flexible operation. If no regulation signals were considered, the algorithm would follow only the left branch (regulating signal: none). The different paths of the algorithm ended up in 4 different operation modes for the heat pump:

- HP part load = heat demand: The heat pump is operated in part load according to the heat demand. 
- HP off: The heat pump is shut-off or remains off.

194

- HP minimum load: The heat pump is operated at lowest part load (150 kW).

195

- HP maximum load: The heat pump is operated at full load. 


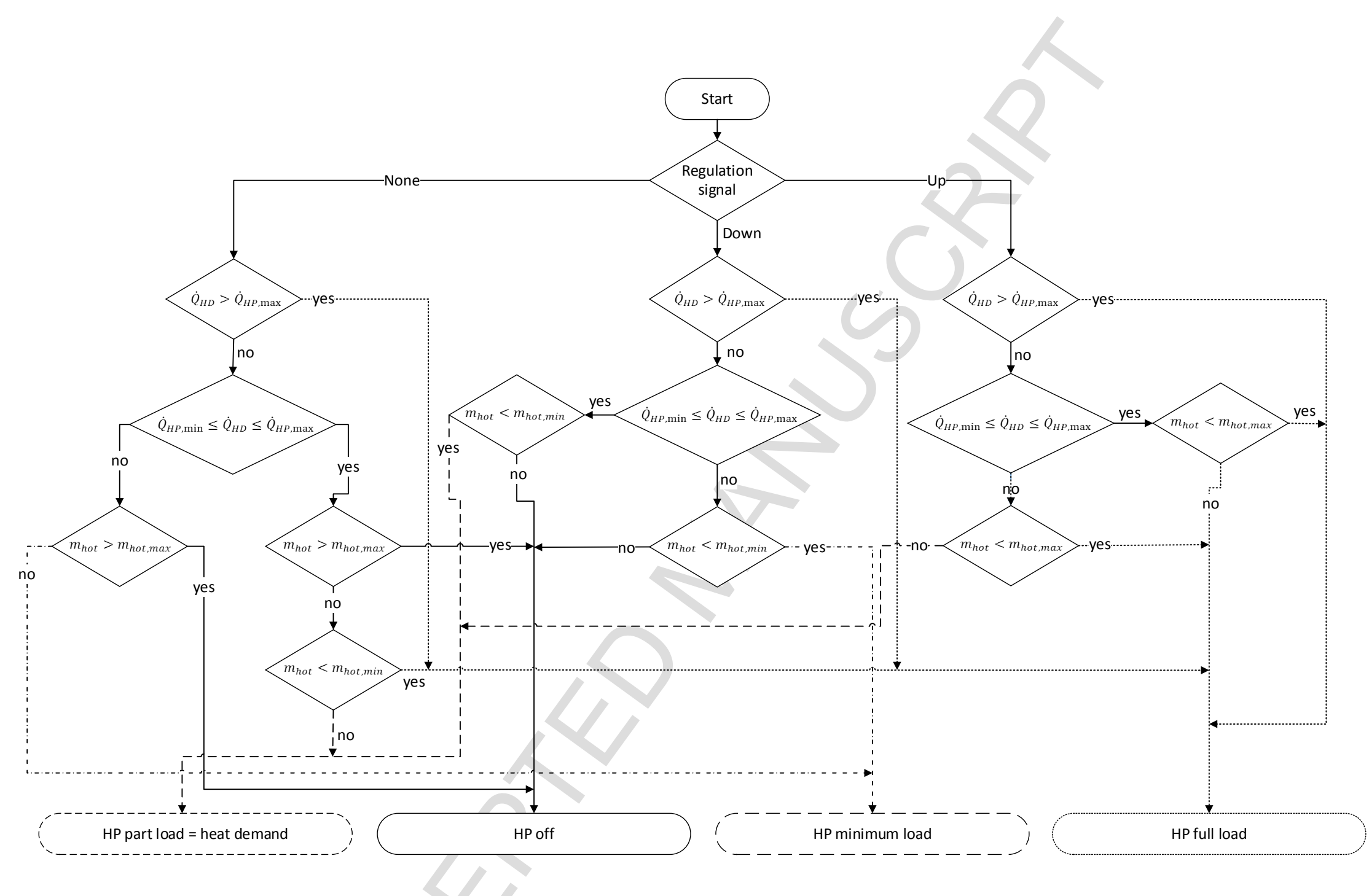

Figure 3 Structure of control algorithm for flexible operation. HD- Heat demand, HP_min/max - Heat pump minimum load/full load, $m \_$hot - mass of hot water in the storage, m_hot_min/max - minimum/maximum mass of hot water in the storage, HD-Heat demand. 
Stratified storage tank

197 The stratified storage tank was modelled using a one dimensional discretization [29] (Figure 4). The tank 198 was divided into 100 layers from top to bottom. For each layer dynamic mass and energy balances were 199 solved. It was assumed that the fluid inside each layer was ideally mixed and thus had constant 200 properties. Heat losses to the environment and between layers were considered. Pressure differences 201 across the tank were neglected as well as increased mixing between the layers during charging and 202 discharging. The minimum and maximum amount of hot water is limited by the inlet design and was 203 assumed to be $1 / 12$ and $11 / 12$ of the total stored mass, respectively.

\subsection{Exergy analysis}

205 As reference state the groundwater temperature $\left(T_{0}=10.5^{\circ} \mathrm{C}\right)$ at atmospheric pressure $\left(p_{0}\right.$ $206=1.013$ bar) was chosen. The groundwater temperature was assumed to be constant throughout the 207 year. All material streams were assumed to be water and no reactions occur at any place in the system. So, the chemical exergy would be equal for all streams and can be neglected [17].

To conduct the exergy analysis of the system, balance equations were formulated for all components.

The balance equation for a general control volume can be formulated as

$$
\frac{d E}{d t}=\sum_{i} \dot{m}_{i} \cdot e_{i}+\sum_{j} \dot{E}_{Q, j}+\sum_{l} \dot{W}_{l}-\dot{E}_{L}-\dot{E}_{D}
$$

211 where $E$ is the exergy content of the control volume, the first sum denotes the exergy content of the

212 material streams entering and exiting the control volume which is calculated as the product of mass flow

$213 \dot{m}$ and specific exergy $e$. The second sum is the sum of all exergy flows related to heat flows $\dot{E}_{Q, j}$ and the

214 third sum considers power flows $\dot{W}_{l} . \dot{E}_{L}$ is the exergy loss to the environment and $\dot{E}_{D}$ denotes the

215 exergy destruction within the control volume. All entering flows are accounted as positive by sign convention. 
217 For the exergy analysis, exergy fuel and product were defined for all components (Table 2). The exergy

218 efficiency of every component can be calculated according to:

$$
\epsilon_{k}=\frac{\dot{E}_{P, k}}{\dot{E}_{F, k}}
$$

Table 2 Exergy fuel and -product and specific cost per unit of exergy fuel and product for the components used in the case study. Charging and discharging refer to charging/discharging of the storage tank. When there is no flow in or out of the tank, the equations for discharging are valid.

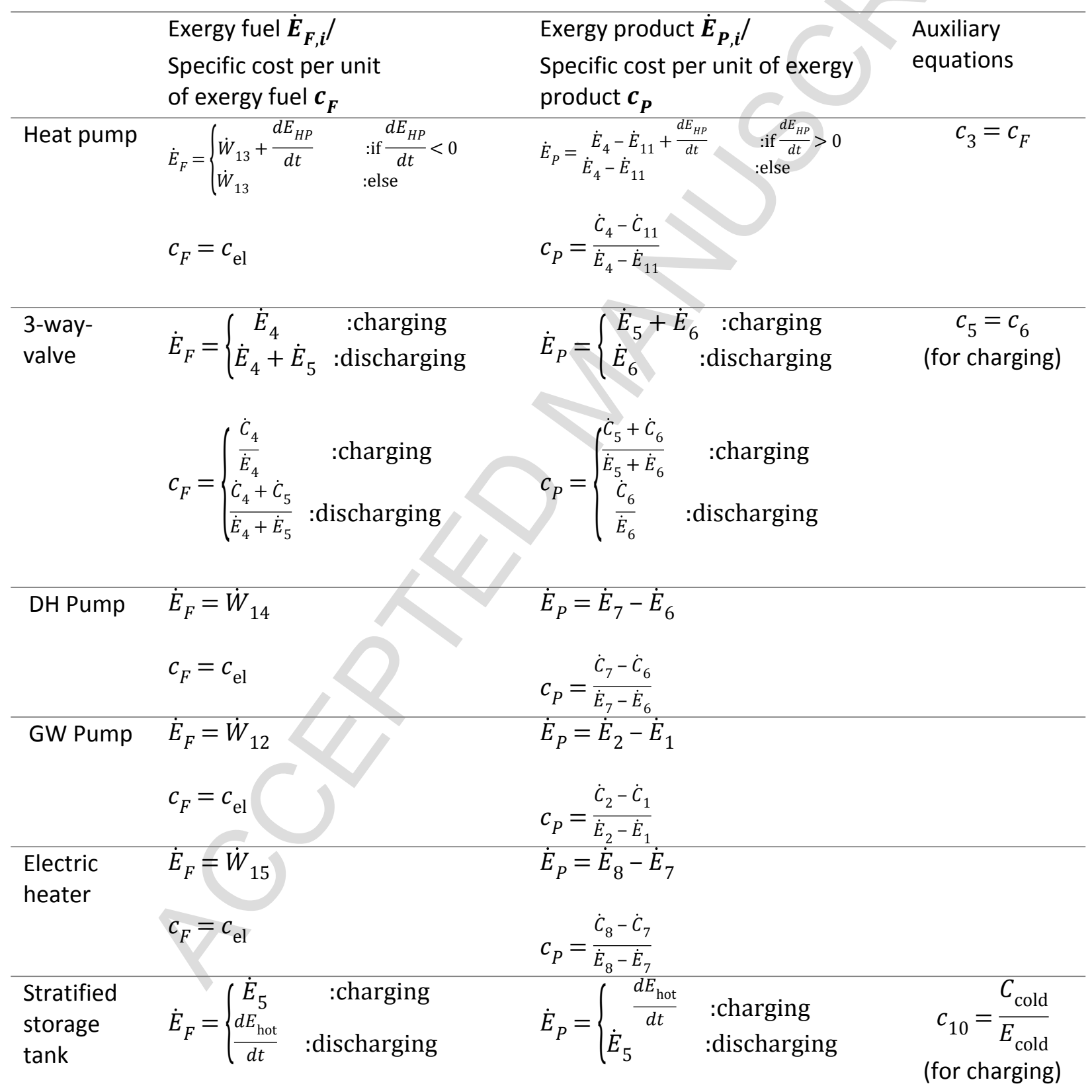




$$
c_{F}=\left\{\begin{array}{lr}
\dot{C}_{5} & \text { :charging } \\
\frac{d C_{\text {hot }}}{d t} & : \text { discharging }
\end{array} \quad C_{P}= \begin{cases}\frac{d C_{\text {hot }}}{d t} & \text { :charging } \\
\dot{C}_{5} & : \text { discharging }\end{cases}\right.
$$

219 Heat pump

220 The exergy efficiency of the heat pump was defined as the increase of exergy of the DH water in the

221 condenser over the power input into the compressor. As the groundwater was cooled down from the

222 reference state temperature in the evaporator, it's exergy content increased. However, the cold stream

223 was not a useful product in this case as it was discharged into the environment and represented an

224 exergy loss of the system. A cost can be assigned to the exergy loss by assuming that the exergy loss is

225 covered through the supply of a corresponding amount of fuel (auxiliary equation) [30].

226 Three-way-valve

227 The three-way-valve controlled the mass flow to and from the stratified storage tank. The exergy fuel

228 and product were different during charging or discharging of the tank. The purpose of mixing in the

229 three-way-valve was to vary between two different heat sources (the heat pump and the storage) and

230 not to heat up the stream from the storage using the stream from the heat pump. Thus the above

231 definition of exergy fuel and product is chosen [17].

232 Stratified storage tank

233 To define the exergy fuel and product of the stratified storage tank, the tank was divided into a hot and

234 a cold control volume (Figure 4). We assumed that the purpose of the tank is to store hot water, and

235 that the cold water is only used to fill up the tank volume that is not used by the hot water. Both control

236 volumes were thus variable in size and additional mass balances for the control volumes are needed.

$$
\begin{gathered}
m_{\text {hot }}+m_{\text {cold }}=\bar{\rho} \cdot V_{\text {storage }} \\
m_{\text {hot }}=\frac{N_{\text {hot }}}{N} \cdot \bar{\rho} \cdot V_{\text {storage }}
\end{gathered}
$$


$237 m_{h o t}{ }^{\prime} m_{\text {cold }}$ denote the mass of the hot and cold control volumes, respectively. $N_{h o t}$ is the number of

238 layers with hot fluid which are defined as all layers with a temperature above $60{ }^{\circ} \mathrm{C}, \bar{\rho}$ is the mean water 239 density in the storage and $V_{\text {storage }}$ is the overall volume of the storage tank. Calculating $m_{\text {hot }}$ in the 240 presented way, has the advantage that the mass flow from the hot to the cold volume due to decrease 241 in temperature can be easily accounted for.

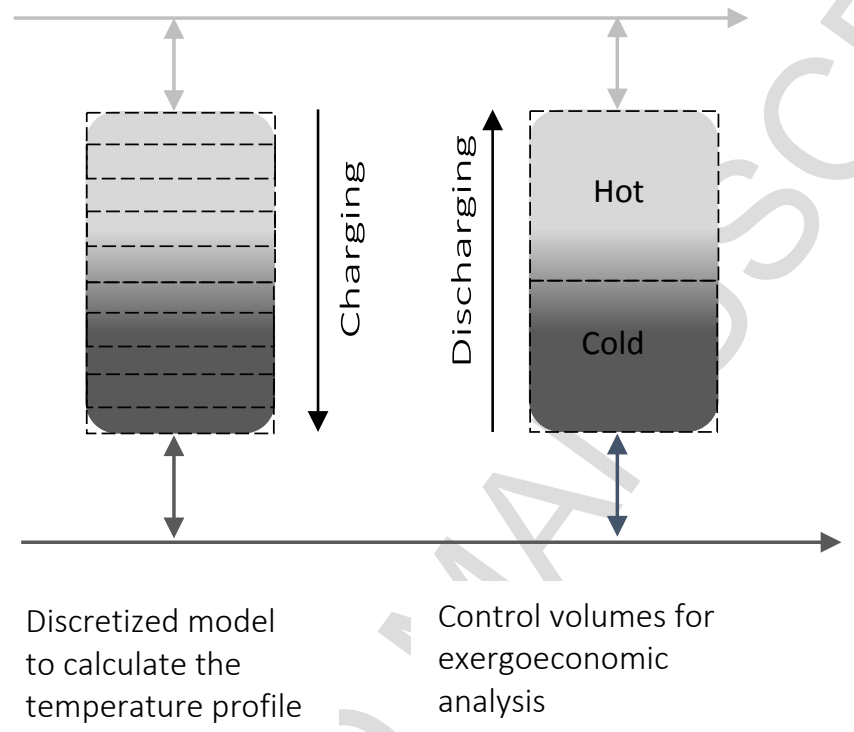

Figure 4 One-dimensional discretization of storage tank and division into hot and cold control volume

242 The exergy fuel during charging was defined as the exergy of the hot water coming in at the top of the

243 tank (stream 5) and the product was the increase in stored exergy inside the hot control volume of the 244 tank. The amount of stored exergy was calculated for both control volumes as

$$
\begin{gathered}
\frac{d\left(E_{\text {hot }}+E_{\text {cold }}\right)}{d t}=\dot{m}_{5} \cdot e_{5}-\dot{m}_{10} \cdot e_{10}-\dot{E}_{D} \\
E_{\text {hot }}=\sum_{n=1}^{N_{\text {hot }}}\left(m_{n} \cdot e_{n}\right)
\end{gathered}
$$

245 where $E_{h o t}, E_{\text {cold }}$ denote the exergy stored in the hot and cold volume respectively. $m_{n}$ is the mass and

$246 e_{n}$ the specific exergy of layer $n$. The volume work due to variation of the control volume size was found 
247 to be small compared to the exergy of stored heat and was neglected. The heat loss from the storage is

248 accounted for as exergy destruction $\dot{E}_{D}$. Assuming that the water in the tank behaves as an ideal liquid,

249 the specific exergy $e_{n}$ for every discretization layer can be calculated from temperatures obtained from

250 the energy balances for every control volume [31].

$$
e_{n}=c_{p, \mathrm{H}_{2} \mathrm{O}} \cdot\left(T_{n}-T_{0}\right)-T_{0} \cdot c_{p, \mathrm{H}_{2} \mathrm{O}} \cdot \ln \left(\frac{T_{n}}{T_{0}}\right)
$$

251 An overall exergy efficiency for the storage was calculated as the ratio of the integrals of the output

252 from - and the input into the hot control volume.

$$
\epsilon_{\text {storage }, \text { tot }}=\frac{\int \dot{E}_{5, \text { out }} d t}{\int \dot{E}_{5, \text { in }} d t}
$$

253 System exergy efficiency

254 The exergy efficiency of the overall system for every time step had to take the storage of exergy in the 255 storage tank into consideration. During charging the exergy stream into the storage represented a

256 product of the system, whereas during discharging the exergy stream out of the tank was a fuel to the

257 overall system:

$$
\epsilon_{\text {system }}=\mid \begin{gathered}
\frac{\dot{E}_{\text {heat }}+\frac{d\left(E_{\text {hot }}+d E_{\text {cold }}\right)}{d t}}{\sum_{k} \dot{W}_{k}} \\
\frac{\dot{E}_{\text {heat }}}{\sum_{k} \dot{W}_{k}+\left|\frac{d E_{\text {hot }}+d E_{\text {cold }}}{d t}\right|}
\end{gathered} \text { if charging }
$$

258 The annual mean exergy efficiency was calculated according to the following equation. 


$$
\epsilon_{\text {system,tot }}=\frac{E_{\text {heat }}}{\sum_{k} W_{k}}
$$

$259 E_{\text {heat }}$ denotes the overall amount of exergy of heat supplied per year and $W_{k}$ is the overall amount of 260 electric energy of component $k$ per year.

\subsection{Exergoeconomic analysis}

262 Within an exergoeconomic analysis a cost is assigned to all exergy streams. This allows to determine the cost of exergy destruction in every component, which can give useful information about the sources of costs throughout the system and how they can be lowered [17].

In order to assign a cost to every exergy stream a dynamic cost balance for every component was set up,

$$
\frac{d C}{d t}=\sum_{i} \dot{C}_{i}+\sum_{k} c_{\mathrm{el}} \cdot \dot{W}_{k}+\dot{Z}
$$

$266 C$ denotes the cost that accumulates within the component, $\dot{C}_{i}$ is the cost streams associated with

267 material streams, $c_{\text {el }}$ is the electricity cost in the respective time step and $\dot{Z}$ denotes the levelized cost

268 stream of the component. The cost stream of the component includes investment cost, capital cost, and 269 operation and maintenance costs for the estimated lifetime of the respective component. It was

270 calculated as described in [17]. However, the cost was not levelized to the full load hours per year but to

271 the actual operation hours per year and $\dot{Z}$ was only considered when the respective component was in

272 operation. The $\mathrm{DH}$ network was existent and we assumed that the operation and maintenance costs are

273 the same for any kind of heat supplying system. Thus, the costs of the DH network were neglected in the 274 present work.

275 The economic data used to calculate $\dot{Z}$ is summarized in Table 3. An average annual discount rate of $4 \%$ 276 and a nominal escalation rate of $2 \%$ for operation and maintenance cost was assumed [32]. 
277 The cost of electricity used in this study is historic spot market prices for Eastern Denmark 2012 from

278 NordPool [33]. 59 DKK/MWh transmission net tariff and 24 DKK/MWh system tariff were included [33].

279 Administration, and trading and unbalance cost were assumed to be $3 \mathrm{DKK} / \mathrm{MWh}$ and $2 \mathrm{DKK} / \mathrm{MWh}$,

280 respectively.

Table 3 Economic data case study

\begin{tabular}{|c|c|c|c|c|c|c|}
\hline \multirow[t]{2}{*}{ Unit } & \multirow[t]{2}{*}{ Capacity } & \multirow{2}{*}{$\begin{array}{l}\text { Total } \\
\text { capital } \\
\text { investment } \\
\text { [DKK] }\end{array}$} & \multirow{2}{*}{$\begin{array}{l}\text { Plant } \\
\text { economic } \\
\text { life } \\
\text { [a] }\end{array}$} & $\begin{array}{l}\text { Operation hours } \\
\text { per year } \\
{[\mathrm{h} / \mathrm{a}]}\end{array}$ & \multirow{2}{*}{$\begin{array}{l}\text { Fixed O\&M } \\
\text { cost 1st } \\
\text { year } \\
{[\text { DKK] }}\end{array}$} & \multirow[t]{2}{*}{ Source } \\
\hline & & & & Non-flex. & & \\
\hline Heat pump & $800 \mathrm{~kW}$ & 560.000 & 25 & 6917 & 3000 & {$[34]$} \\
\hline El. heater & $200 \mathrm{~kW}$ & 150.000 & 20 & 1233 & 220 & {$[34]$} \\
\hline DH pump & $2 \times 16.7 \mathrm{~kg} / \mathrm{s}$ & 30.000 & 10 & 8760 & 440 & {$[23]$} \\
\hline GW pump & $2 \times 44.3 \mathrm{~kg} / \mathrm{s}$ & 40.000 & 10 & 7527 & 440 & {$[23]$} \\
\hline Storage tank & $120 \mathrm{~m}^{3}$ & 31.200 & 40 & 8760 & 700 & {$[34]$} \\
\hline Drilling & & 900.000 & 40 & 6917 & 18000 & {$[35$} \\
\hline
\end{tabular}

\subsection{Allocation of cost}

282 The allocation of cost to both products of the heat pump system, i.e. heat supply and provision of demand flexibility, is a central question when operating energy conversion units in an integrated energy

284 system. The characteristics of both products are different. Heat is an output from the system and so is

285 the related heating service. Electricity is an input into the system, but the corresponding flexibility is a

286 service provided by the system, see Figure 5. The cost of providing flexibility is not directly connected to

287 the electricity stream and all extra cost will be reflected in the heat generation cost. However, as the

288 source of cost difference was not the supply of heat but the additional exergy destruction due to the

289 provision of flexibility, the cost should be allocated accordingly. The exergy destruction related to

290 flexible operation does not only occur at the same time as the provision of regulation power. Thus, we

291 chose an integral approach to determine the cost related to flexible operation. 


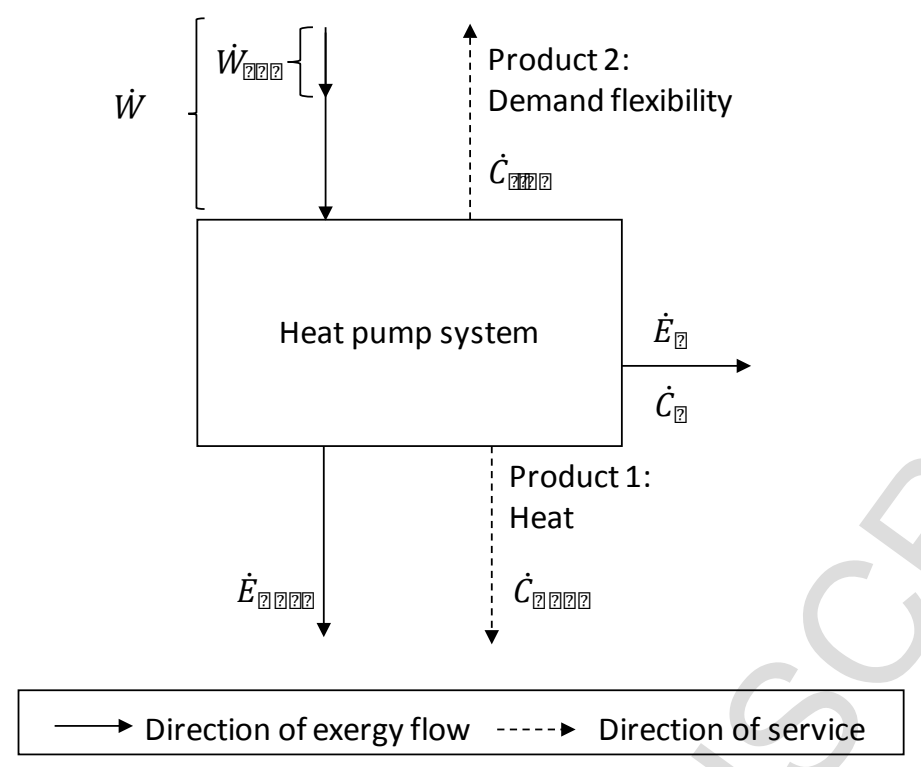

Figure 5 Direction of energy flow and product delivery for a conversion unit in an integrated energy system

292 As the flexibility provided to the electricity sector was not directly connected to an exergy product

293 stream, the cost was allocated according to the increased exergy destruction due to flexible operation,

294 which was given as the difference between the overall exergy destruction in the flexible and the non-

295 flexible case. The specific cost per unit of exergy was calculated as:

$$
c_{\text {ex }}=\frac{\left(C_{\text {heat }}+C_{L}\right)}{E_{\text {heat }}+\left(E_{D, \text { flex }}-E_{D, \text { nonflex }}\right)}
$$

296 The overall cost exiting the system is the sum of the integrated cost of heat $C_{\text {heat }}$ and of the exergy loss

$297 C_{L} . E_{\text {heat }}$ is the integrated amount of exergy supplied as heat to the $\mathrm{DH}$ grid and $E_{D, \text {,lex }}, E_{D, \text { nonflex }}$ is the 298 overall exergy destruction caused during flexible operation and non-flexible operation, respectively. All 299 values were calculated by integrating the respective cost and exergy flow rates over one year.

300 Knowing the overall cost related to flexible operation per year, the specific cost per unit of regulating 301 energy $W_{\text {reg }}$ provided can be determined. 


$$
c_{\text {flex }}=\frac{c_{\text {ex }} \cdot\left(E_{D, \text { flex }}-E_{D, \text { nonflex }}\right)}{W_{\text {reg }}}
$$

302 In order to be able to compare different units, we also calculate the annual specific cost of flexible

303 operation per kW installed electric capacity $\dot{W}_{\text {installed }}$

$$
c_{\text {flex, capacity }}=\frac{c_{\text {ex }} \cdot\left(E_{D, \text { flex }}-E_{D, \text { nonflex }}\right)}{\dot{W}_{\text {installed }} \cdot 8760 \cdot 3600 \mathrm{~s} / \mathrm{a}}
$$

304 The heat generation cost is calculated from the overall cost delivered into the $\mathrm{DH}$ grid over the overall

305 amount of heat.

$$
c_{\text {heat }}=\frac{c_{\text {ex }} \cdot E_{\text {heat }}}{Q_{\text {heat }}}
$$

306

307

\section{Results}

To calculate the performance of the system when operated flexibly the system was simulated and the exergoeconomic analysis was carried out for two different cases:

A. Non-flexible operation- the heat pump is not operated according to regulation requests from the grid, but only according to heat demand. This means the heat pump is mostly operating in part load.

B. Flexible operation according to regulatory signal - the heat pump is controlled according to the heat demand, the state of storage and a regulatory signal to provide flexibility. This control strategy was presented previously in chapter 2.2, Figure 3.

Figure 6 shows the heat load at the heat pump condenser for the non-flexible and flexible operation.

The non-flexible operation followed the heat demand apart from the periods, where the heat demand was lower than the lowest allowable part load of the heat pump (150 kW). In that case, the heat pump 
was operated at minimum part-load until the storage was filled to the maximum, then the heat demand was supplied from the storage and the heat pump was switched off until the storage was emptied.

In the case of flexible operation the heat pump load changed frequently. When down- or up-regulation was requested, the system ramped up to full load or shut down, if possible. When there was no regulation signal, the heat load at the condenser followed the heat demand.

\section{Non-flexible (part-load) operation}

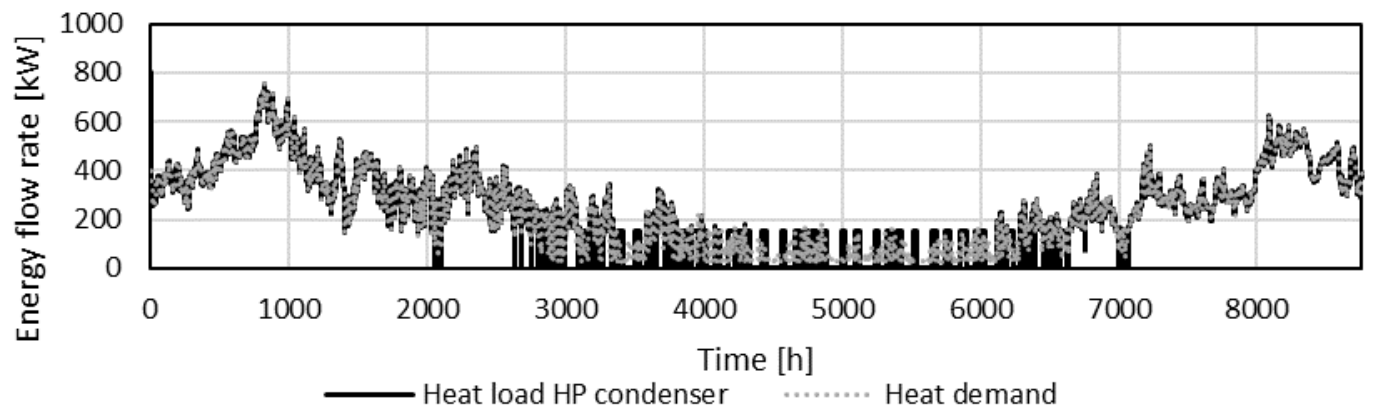

\section{Flexible operation}

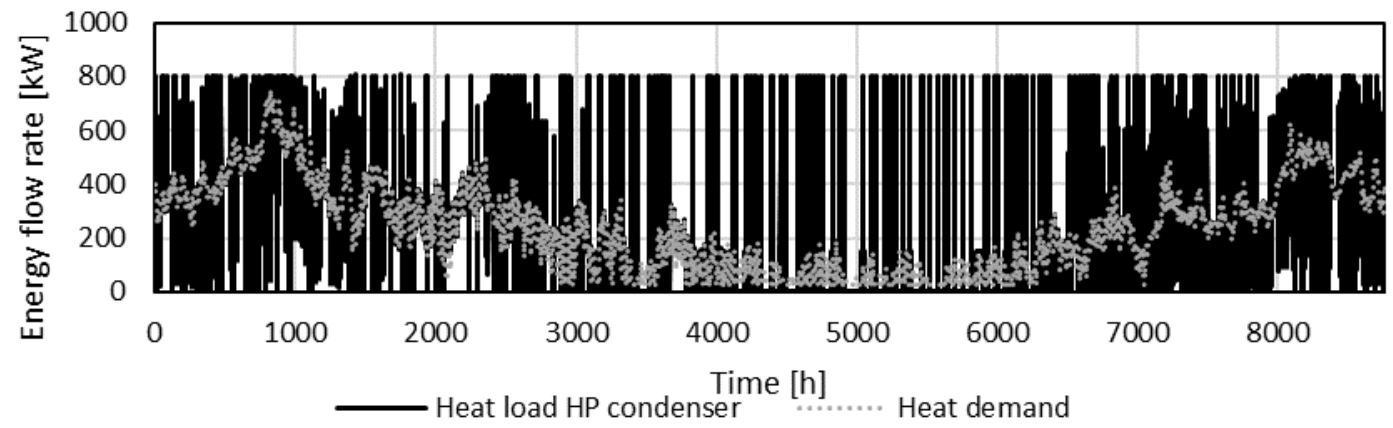

Figure 6 Heat load at heat pump condenser and heat demand for non-flexible operation and flexible operation for one year (2012)

323 The overall power uptake was higher for flexible operation (Table 4). This was mainly due to reheating

324 the water from the storage in the electric heater. The electric heater consumption increased from 37

$325 \mathrm{MWh} /$ year to $85 \mathrm{MWh} /$ year. The power uptake of the heat pump was slightly lower during flexible 
operation. The seasonal heat pump COP was the same for both operation modes, whereas the seasonal

327 SCOP was lower for the flexible case.

328 The overall exergy input into the system is given as the sum of all electric energy inputs into the system.

329 The exergy provided to the heat pump accounts for $84.5 \%$ and $79.4 \%$ of the overall exergy input in the 330 non-flexible and flexible case, respectively.

Table 4 Energetic performance indicators

\begin{tabular}{llrr}
\hline & & $\begin{array}{l}\text { Non- } \\
\text { Flexible } \\
\text { operation }\end{array}$ & $\begin{array}{l}\text { Flexible } \\
\text { operation }\end{array}$ \\
\hline Heat pump electric energy consumption & {$[\mathrm{MWh} / \mathrm{a}]$} & 582 & 577 \\
Electric heater electric energy consumption & {$[\mathrm{MWh} / \mathrm{a}]$} & 37 & 85 \\
GW pump electric energy consumption & {$[\mathrm{MWh} / \mathrm{a}]$} & 40 & 35 \\
DH pump electric energy consumption & {$[\mathrm{MWh} / \mathrm{a}]$} & 30 & 30 \\
Total electric energy consumption & {$[\mathrm{MWh} / \mathrm{a}]$} & 689 & 728 \\
Heat supplied to DH system & {$[\mathrm{MWh} / \mathrm{a}]$} & 2125 & 2125 \\
Overall heat loss within the conversion system & {$[\mathrm{MWh} / \mathrm{a}]$} & 5.9 & 41.2 \\
Seasonal heat pump COP & {$[-]$} & 3.60 & 3.60 \\
Seasonal system COP (SCOP) & {$[-]$} & 3.09 & 2.92 \\
Exergy of heat & {$[\mathrm{MWh} / \mathrm{a}]$} & 293 & 293 \\
Total exergy destruction & {$[\mathrm{MWh} / \mathrm{a}]$} & 360 & 399 \\
Overall exergy loss & {$[\mathrm{MWh} / \mathrm{a}]$} & 43.6 & 43.4 \\
Overall exergy efficiency & {$[\%]$} & $42.6 \%$ & $40.3 \%$ \\
\hline
\end{tabular}

\subsection{Exergy analysis}

332 Error! Reference source not found. shows the exergy destruction within the major components for a week in February. When the heat pump turned on, the exergy destruction in the heat pump increased

334 rapidly and leveled out to a steady state value. The exergy destruction of the heat pump increased with 335 the overall power input. When the heat pump turned off, the exergy destruction in the heat pump 336 decreased to zero. The exergy efficiency peaked at these times because the heat supplied from the upper layers of the storage had a high enough temperature to supply the DH grid directly. When the 

desired temperature. The exergy efficiency decreased accordingly.

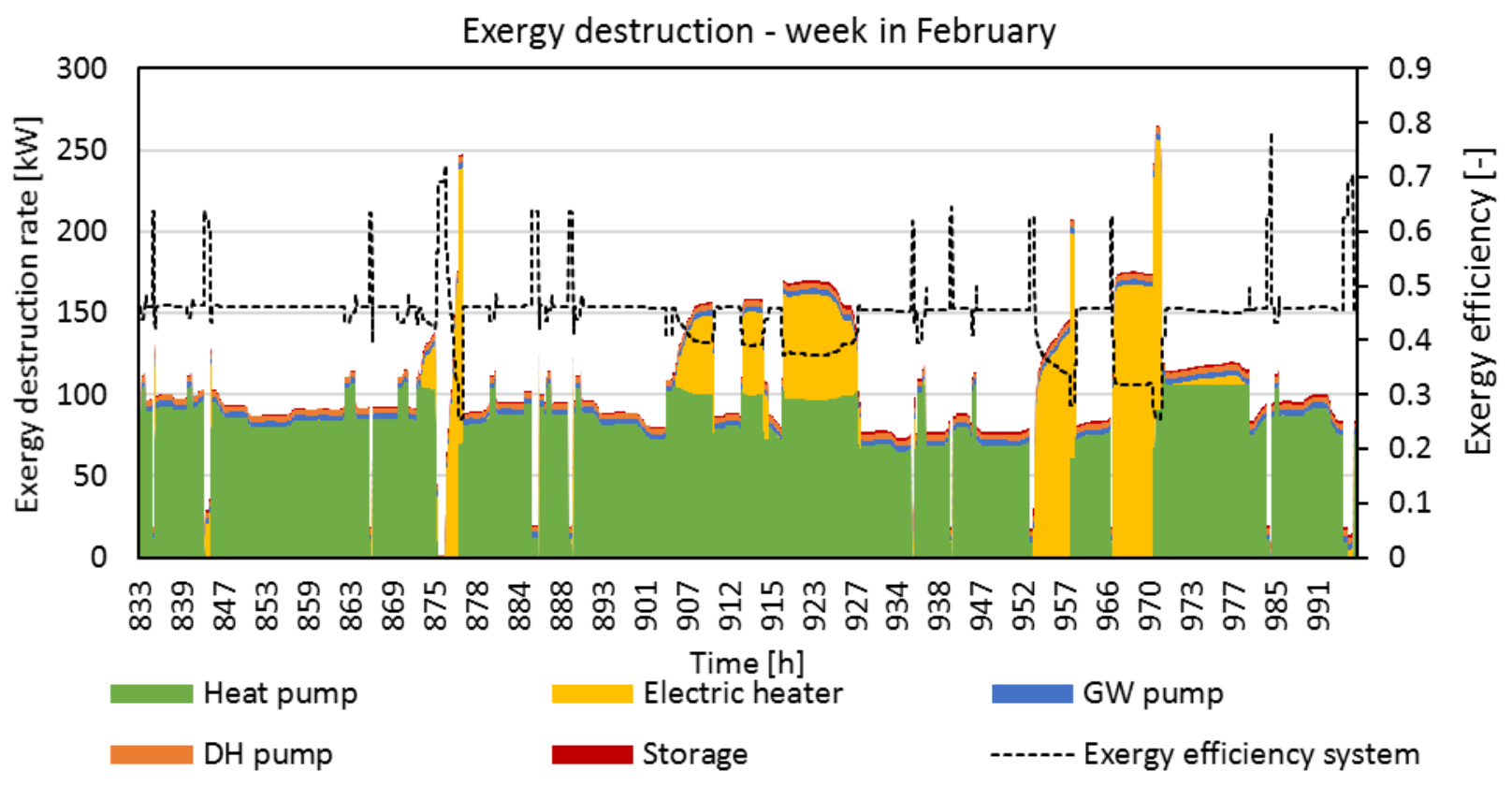

Figure 7 Exergy destruction (ED) rates during flexible operation for major components

341 The component exergy efficiencies are presented in Figure 8 for the same week. The heat pump exergy

342 efficiency was constant during operation (Figure 8 (a)). Peaks only occurred during ramping and shut-off.

343 This is due to the heat stored in the heat pump components, which is still available during shut-down..

344 The exergy efficiency of the electric heater is lower than the HP efficiency with approx. $17 \%$.

345 The exergy efficiency of the groundwater pump was highest when the heat pump was operated at full

346 load, i.e. at nominal conditions. Accordingly, the exergy efficiency decreased with decreasing mass flow.

347 The exergy efficiency of the storage was above $90 \%$ when the storage was charged or discharged

348 (Figure 8 (c)). Losses from the storage also occurred when the storage was not operated. Thus, the mean 349 exergy efficiency of the storage was calculated as approx. $86.3 \%$. 
a) Exergy efficiency of HP and electric heater

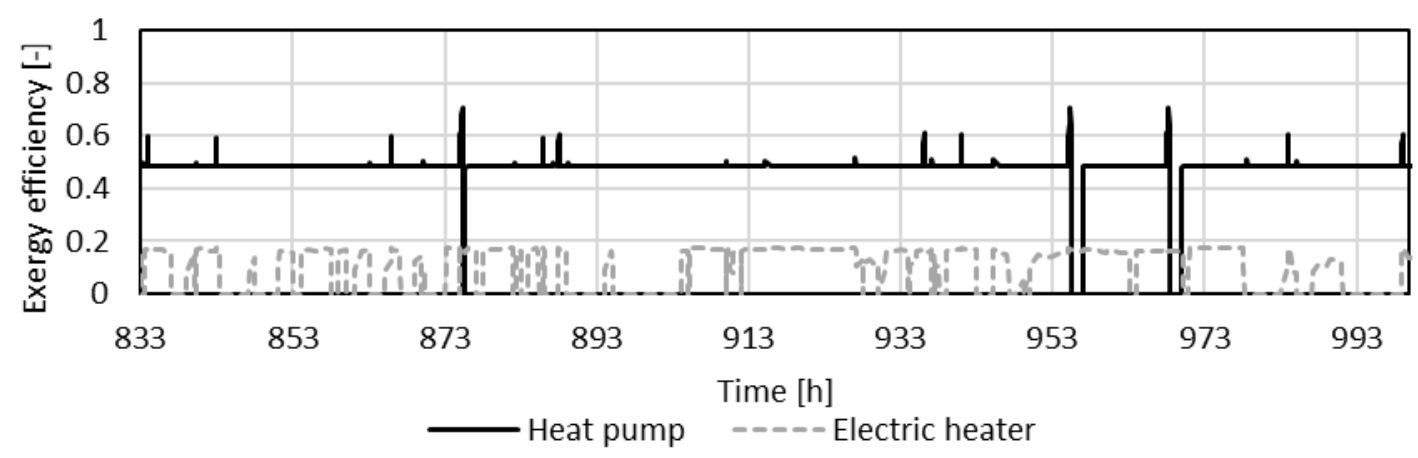

b) Exergy efficiency of GW pump and DH pump

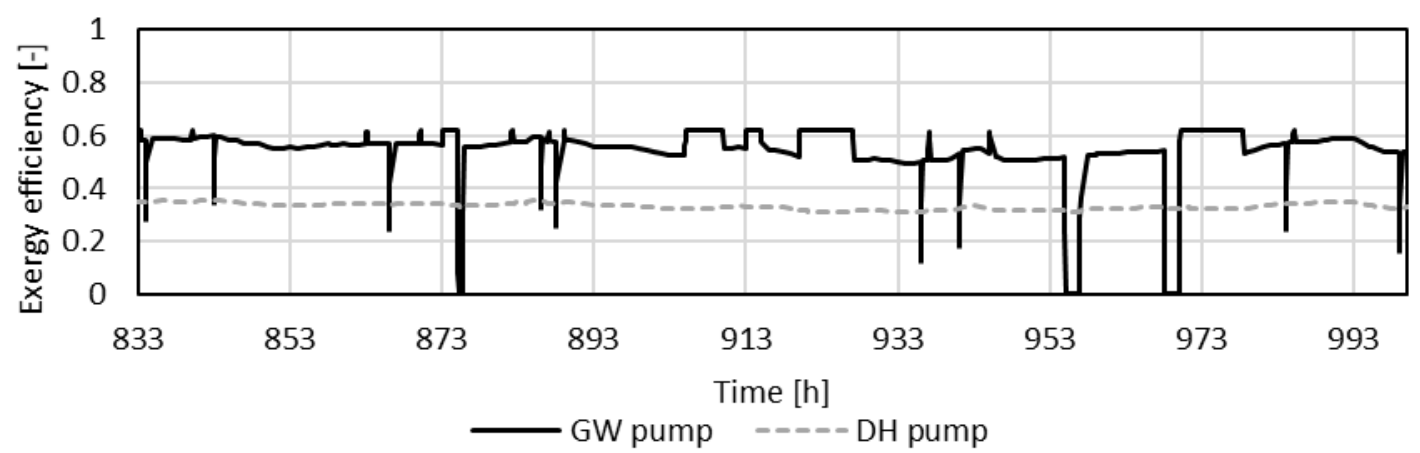

c)

Exergy efficiency of HP and electric heater

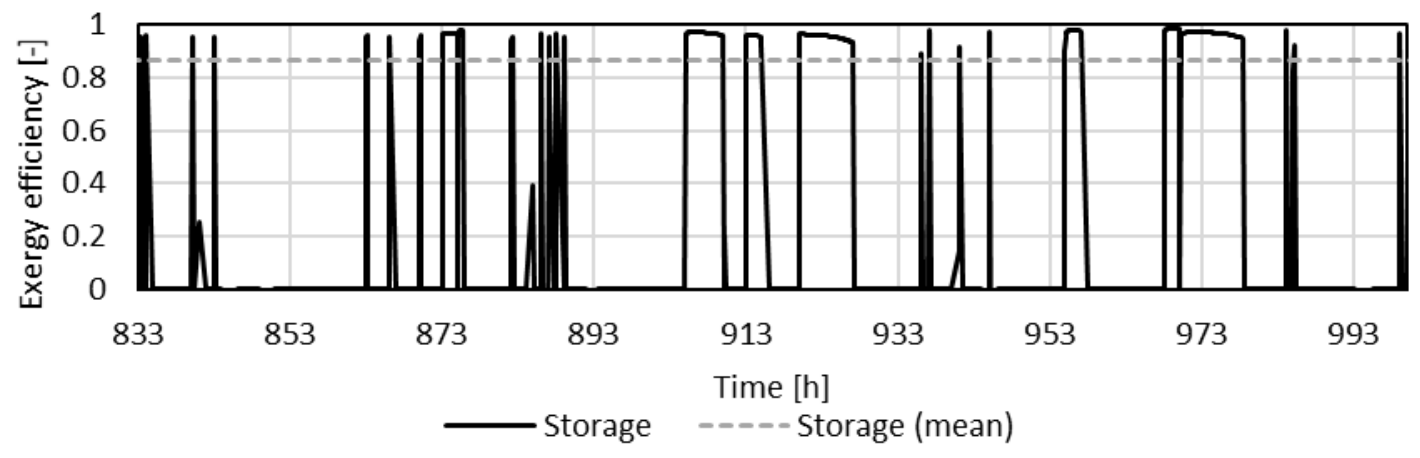

Figure 8 Exergy efficiency of major components for flexible operation

351 Figure 9 shows the exergy content of the storage for the first thousand hours of the year for flexible

352 operation. The amount of exergy stored as hot water increased during charging and the exergy content

353 of the cold water decreased accordingly. When the storage was not charged or discharged over a longer

354 period, the exergy content decreased slowly due to heat losses. 


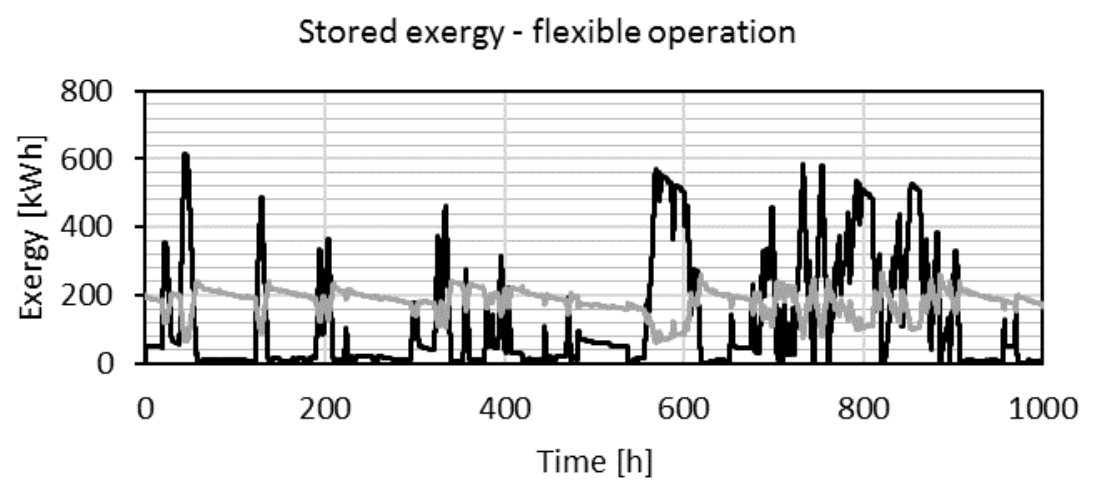

- Hot control volume Cold control volume

Figure 9 Exergy content of hot and cold control volume of the stratified storage tank for the first 1000 hours of the year 2012

355

356

357

358

\subsection{Exergoeconomic analysis}

Figure 10 shows the condenser load of the heat pump and the overall specific cost per unit of exergy that was delivered into the DH system. Further, the cost of electricity is shown. The yearly average for eastern Denmark for the year 2012 was $0.3757 \mathrm{DKK} / \mathrm{kWh}$ including the tariffs given in section 2.4.

The specific cost per unit exergy of the non-flexible operation followed the development of the electricity cost (Figure 10). In the flexible operation case, the specific cost increased when the heat pump was turned off, as the heat had to be delivered from the storage tank and reheated in the electric boiler. The flow taken from the storage tank had a higher specific cost than that fed into it due to the cost of exergy destruction in the tank and the levelized cost of the tank. The cost was accounted to the exergy stored in the warm control volume of the tank. The exergy destruction and levelized cost of the electric boiler further increased the specific cost. The specific cost did not differ significantly between the flexible and non-flexible operation while the heat pump is running. The mean specific fuel cost (spot market prices) during regulation was found to be slightly higher than the yearly average. 
Heat pump load

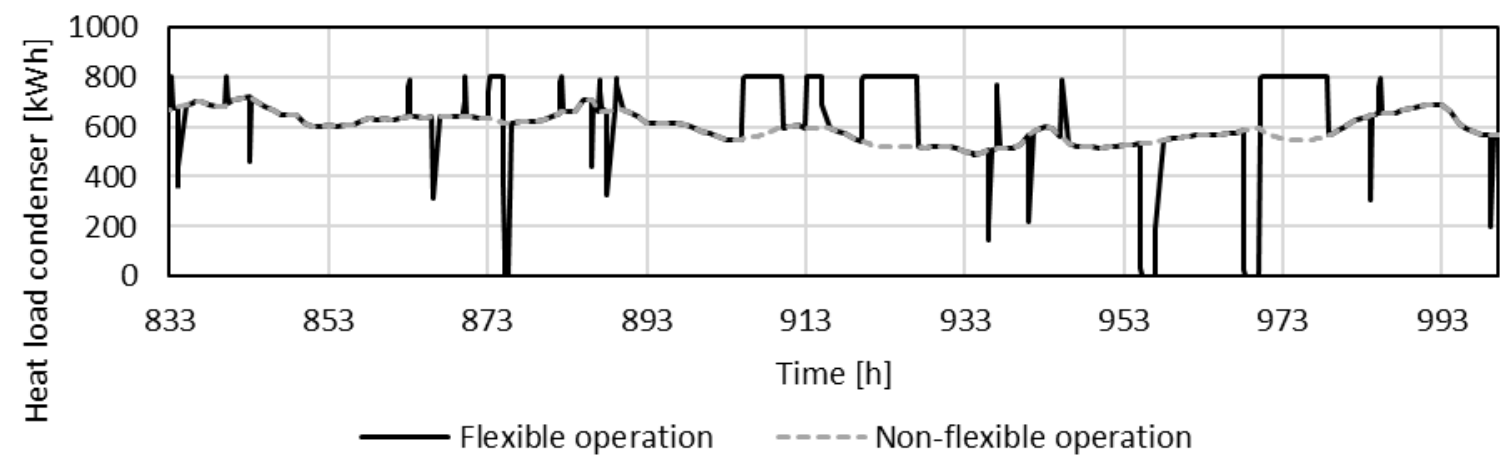

Specific cost per unit exergy

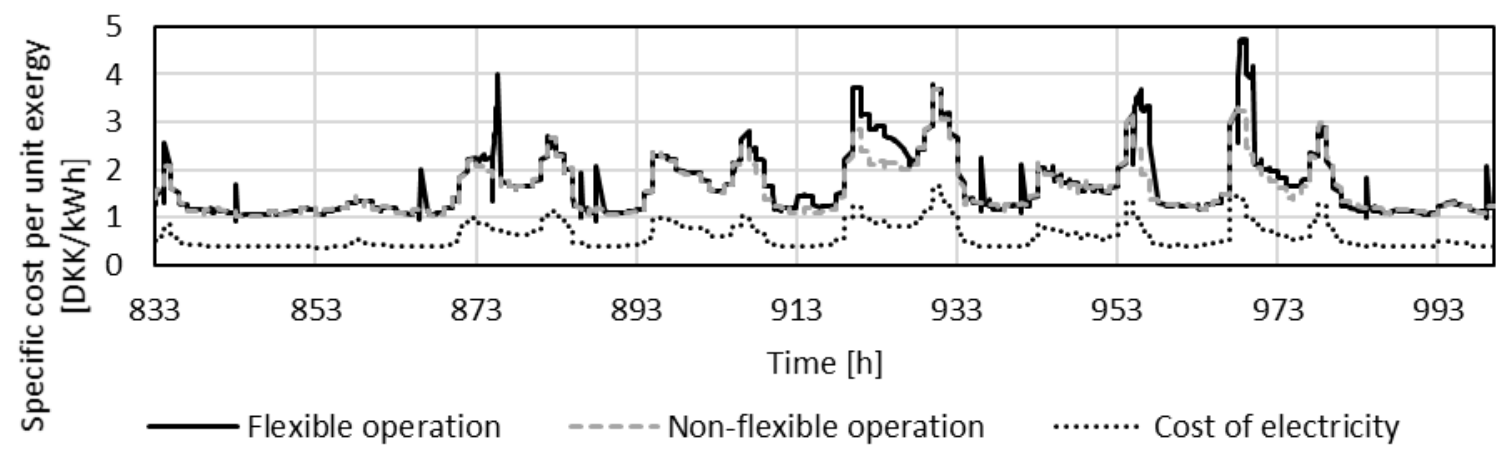

Figure 10 Heat load condenser, overall product cost for non-flexible and flexible operation and cost of electricity for a week in February 2012

The regulation energy that was available from the heat pump system is shown in Table 5. The response rate given here is the ratio between the time where the system reacted to a regulation signal and the time where the system received a regulation signal. The response rate was lower for down-regulation,

371 while the overall regulation energy was approx. six times larger than for up-regulation.

372 The specific cost of heat was lower for the flexible operation compared to the non-flexible operation, as

$37312 \%$ of the overall product cost were assigned to the provision of flexibility and the overall cost were

374 reduced. The specific cost per kWh of regulation energy was $0.660 \mathrm{DKK} / \mathrm{kWh}$. This corresponds to an

375 annual cost of flexible operation per kW installed capacity (only heating units) of $65 \mathrm{DKK} / \mathrm{kW} / \mathrm{a}$. The

376 average difference between the balancing price and the electricity spot price, i.e. the possible benefit by 
377 providing balancing services, was $0.133 \mathrm{DKK} / \mathrm{kWh}$ for down-regulation and $0.208 \mathrm{DKK} / \mathrm{kWh}$ for up-

378 regulation for 2012 [28]. The corresponding values for 2017 were found to be even lower with 0.093

$379 \mathrm{DKK} / \mathrm{kWh}$ for down-regulation and 0.153 for up-regulation. During individual hours the benefit of

380 performing the service could be higher. For 2012 it was found that in $180 \mathrm{~h}$ out of $3101 \mathrm{~h}$ where

381 balancing power was needed the benefit provided was larger than $0.660 \mathrm{DKK} / \mathrm{kWh}$, this corresponds to

$3825.8 \%$ of the hours where balancing services where provided.

Table 5 Amount of regulation energy and heat and specific cost of both products

\begin{tabular}{|c|c|c|c|c|c|c|}
\hline & $\begin{array}{l}\text { Non- } \\
\text { flexible } \\
\text { operation }\end{array}$ & $\begin{array}{l}\text { Flexible } \\
\text { operation }\end{array}$ & $\begin{array}{l}\text { Flexible } \\
\text { operation } \\
\text { - Winter }\end{array}$ & $\begin{array}{l}\text { Flexible } \\
\text { operation } \\
\text { - Spring }\end{array}$ & $\begin{array}{l}\text { Flexible } \\
\text { operation } \\
\text { - Summer }\end{array}$ & $\begin{array}{l}\text { Flexible } \\
\text { operation } \\
\text { - Autumn }\end{array}$ \\
\hline Heat [MWh/a] & 2125 & 2125 & 965 & 540 & 155 & 464 \\
\hline Up-regulation [MWh/a] & 0 & 67.8 & 18.5 & 14.2 & 15.6 & 19.5 \\
\hline Down-regulation [MWh/a] & 0 & 11 & 0.99 & 0.72 & 5.49 & 4.02 \\
\hline Response rate Down-regulation [\%] & 0 & $37 \%$ & $33 \%$ & $48 \%$ & $34 \%$ & $39 \%$ \\
\hline Response rate Up-regulation [\%] & 0 & $67 \%$ & $27 \%$ & $69 \%$ & $100 \%$ & $76 \%$ \\
\hline Specific heat cost [DKK/kWh] & 0.219 & 0.184 & 0.168 & 0.181 & 0.303 & 0.186 \\
\hline Cost of flexibility [DKK/kWh] & 0 & 0.660 & 1.079 & 0.830 & 0.018 & 0.695 \\
\hline Overall cost [DKK] & 465000 & 443000 & 183000 & 110000 & 47000 & 102000 \\
\hline Overall exergy of heat [MWh] & 293 & 293 & 133 & 75 & 21 & 64 \\
\hline Overall exergy loss [MWh] & & 43 & 20 & 11 & 3 & 9 \\
\hline Overall exergy destruction [MWh] & & 399 & 160 & 103 & 44 & 93 \\
\hline $\begin{array}{l}\text { Additional exergy destruction } \\
\text { [MWh] }\end{array}$ & & 39 & 17 & 9 & 0 & 12 \\
\hline
\end{tabular}

383 The overall cost input into the system is 443000 DKK/a for flexible operation and 464000 DKK/a for non-

384 flexible operation. $37 \%$ and $43 \%$ of the overall cost of flexible and non-flexible operation, respectively,

385 are the levelized cost of operation. The remaining part is the fuel cost of the system.

386 The exergy destruction and the related cost are presented in Figure 11 and Figure 12. The exergy

387 destruction of the heat pump was very similar for both scenarios. This indicates that the increased

388 exergy destruction during load changes did not have a significant influence on the overall exergy 
destruction of the heat pump. The exergy destruction in the groundwater pump was lower in the case of

390 flexible operation, due to part-load operation.

391 The cumulated exergy destruction in the electric boiler was higher during flexible operation compared

392 to non-flexible operation. This is due to an increased amount of heat, which was supplied from the 393 storage and had to be heated up to fulfill the requirement of $70^{\circ} \mathrm{C}$ supply temperature. The exergy 394 destruction in the $\mathrm{DH}$ pump was similar for both cases, as the heat demand, and thus the mass flow rate 395 were the same.

396 The exergy destruction in the storage occurs mainly due to heat losses and is low compared to the other 397 components. The cost of exergy destruction in the storage was responsible for $16 \%$ and $7 \%$ of the 398 overall cost of exergy destruction in flexible and non-flexible operation mode, respectively. The cost 399 related to the exergy destruction in the storage was a larger share of the overall cost. This occurred as 400 the fuel of the storage was the warm inlet, which had a high specific cost due to the cost of the 401 upstream components assigned to it.

Cumulated exergy destruction [MWh/a]

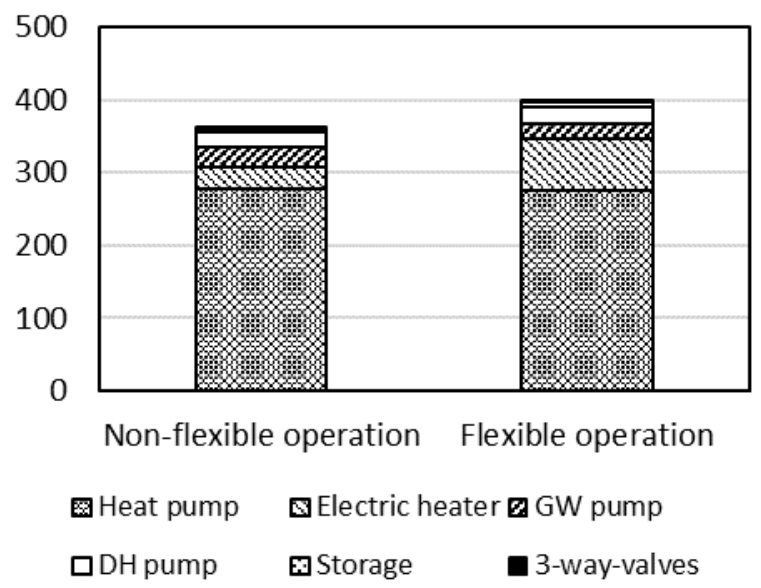

Figure 11 Overall exergy destruction of all components per year for flexible and non-flexible operation

\section{Cumulated cost of exergy destruction $[\mathrm{DKK} / \mathrm{a}]$}

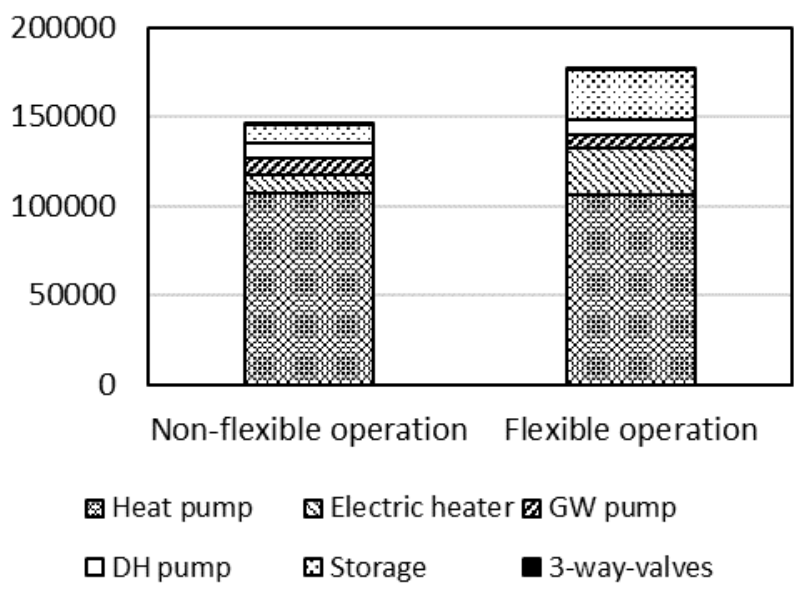

Figure 12 Overall cost of exergy destruction of all components per year for flexible and non-flexible operation 


\subsection{Influence of heat pump capacity}

403 The system assessed here, was oversized for the given heat demand. This was done with the aim to be

404 able to operate the system very flexibly. The simulation was repeated for an increase and decrease of

405 the heat pump capacity of $100 \mathrm{~kW}$ each, keeping all other components and the heat demand the same.

406 The results (Figure 13) indicated that the specific cost of heat is almost constant for all three cases and

407 the overall cost per year increases slightly with increasing HP capacity. Whereas, the specific cost of

408 flexibility decreases considerably with increasing HP capacity. This is caused by two effects. Firstly, an

409 increase in the additional exergy destruction due to flexible operation for larger heat pump capacities

410 leads to a decrease in the specific cost per unit exergy. Secondly and more importantly, the amount of

411 regulation energy provided increases with increased heat pump capacity.

412 The results for the overall exergy destruction and the additional exergy destruction due to flexible

413 operation increased slightly for increased HP capacity. This is due to the lower minimum part-load

414 capacity of the smaller heat pump and thus a higher share of heat that is directly supplied from the heat

415 pump, avoiding exergy destruction in the storage and the electric boiler. 


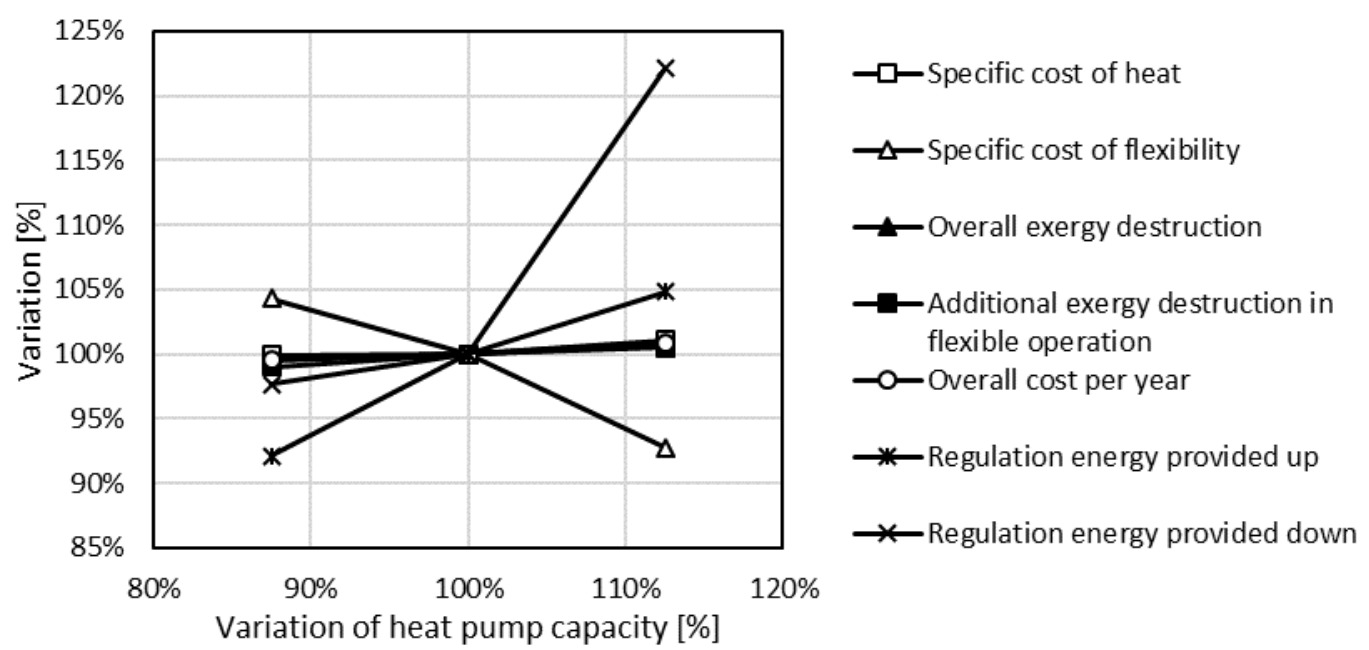

Figure 13 Variation of specific product cost, response rate and exergy destruction in \% over the heat pump capacity in \%

\section{Discussion}

417 A method was presented to value the two products of a heat pump system using a dynamic

418 exergoeconomic analysis. The allocation of cost to the provision of ancillary services was based on the

419 additional exergy destruction in the system. We found that this approach is well suited as it resembles

420 the common exergy costing method closely, e.g. [30], and at the same time the problem of the different

421 directions of exergy flow and service provision (Figure 5) can be handled. Allocating the cost in the

422 presented way, a cost could also be assigned to the flexibility when the overall fuel cost is be lower than

423 in the reference case. The applied approach is based on exergoeconomic theory. Other approaches

424 based on economics or more heuristic assumptions would also be possible and may reach other costs of

425 the flexibility.

426 For the case study of a heat pump island system the flexible operation of the system caused higher

427 exergy destruction and thus fuel consumption. The overall fuel cost and the specific fuel cost were

428 found to be higher during regulation. This is due to the difference between the trends of the electricity

429 spot market price and the regulation requests found in the data for Eastern Denmark in 2012. Also, the 
control algorithm did not consider any kind of optimization, but the system would react to a regulation

431 request whenever possible. In this case the difference between the overall cost for flexible and non-

432 flexible operation was approx. 21000 DKK/a.

433 Further, using the sport market price for the calculation implicates that a perfect prediction of the heat

434 demand can be made. This is of course not possible in reality. The spot market price is also used to

435 calculate the cost during regulation, thereby the cost difference between the flexible and non-flexible

436 case is indeed an opportunity cost of providing flexibility. The comparison showed that the obtainable

437 price at the balancing price was in most cases lower than the additional cost due to losses in the storage

438 and the electric boiler.

439 The additional exergy destruction was mainly caused by heat losses in the storage, which led to

440 reheating of the $\mathrm{DH}$ forward flow and thus exergy destruction in the electric boiler. This result

441 reconfirms findings of previous studies on individual HP systems [36,37]. Reducing heat losses in the

442 storage and the need for reheating, will improve the systems efficiency.

443 No significant difference in the exergy destruction of the heat pump was found. This is related to the

444 assumption that part load characteristics of the heat pump are not considered. The part load

445 performance depends on the capacity control type of the compressor [27], as well as the design of the

446 heat exchangers.

447 The assumption that a largely overdimensioned system can provide more flexibility made when

448 designing the system correlates with the results of the parameter variation that showed that the

449 amount of regulation energy provided increased with increased HP capacity. On the contrary, both the

450 overall cost per year and the exergy destruction in the system increase for larger HPs. Thus, the

451 examination of the optimal component sizes for systems that are designed to provide flexibility may be

452 a topic for further analysis. 
453 The presented work gave an insight into the effect of providing ancillary services on the conversion unit,

454 in this case a heat pump system. The advantage of this approach is that the actual thermodynamic and 455 economic effect of providing flexibility to another sector can be assessed. In this way it is possible to 456 assess the additional amount of electricity used and the part of the conversion units cost that is caused

457 by providing another product. This is valuable information for the heat pump operator and it adds a

458 different perspective to the discussion about how flexibility should be valued. So far the overall system 459 benefit was mostly discussed (e.g. [4], [15], [38]) and the actual effect on the conversion unit was not 460 considered.

\section{Conclusion}

462 Energy conversion units are an essential part of integrated energy systems. They are able to connect 463 different sectors and provide services to both of them. In the case of electricity and heating sector, the 464 conversion units provide heat to the heating system while acting as flexible demand for the electricity 465 sector. A method to assess the impact of flexible operation of a heat pump system was presented, 466 where allocation of the cost of both the heating and the flexibility products was based on a dynamic 467 exergoeconomic analysis.

468 The method was applied to a heat pump island system located in Copenhagen. We found that operation 469 according to regulation request resulted in higher exergy destruction and higher overall cost of the 470 system. The additional exergy destruction was mainly caused by heat losses in the storage and reheating

471 of the forward stream. The cost allocated to the flexible operation was $12 \%$ of the overall cost of the 472 system.

473 Overall, the method gives important insights into the effect of integrating energy systems on the energy 474 conversion units and can thus support the decision making process when considering how to design and 475 operate a conversion unit. 


\section{Acknowledgements}

477 This research project is financially funded by EUDP (Energy Technology Development and

478 Demonstration) under the project "EnergyLab Nordhavn - New Urban Energy Infrastructures" (project

479 number: 64014-0555). 


\section{Nomenclature}

$\begin{array}{ll}\text { Abbreviations } & \\ \text { COP } & \text { Coefficient of performance } \\ \text { DH } & \text { District heating } \\ \text { El. } & \text { Electric } \\ \text { GW } & \text { Groundwater } \\ \text { SCOP } & \text { Seasonal system COP }\end{array}$

\section{Symbols}

\section{C}

c

$\dot{C}$

$c_{p, \mathrm{H}_{2} \mathrm{O}}$

E

$e$

$\dot{E}$

$k_{1}, k_{2}$

$\dot{m}$

$m$

$N$

$p$

$Q$

$\dot{Q}$

$T$

$t$

$T_{m, i}$

$\mathrm{V}$

$\dot{W}$

$\dot{Z}$
Cost

Specific cost per unit exergy

Cost stream

Heat capacity water

Exergy

Specific exergy per unit mass

Exergy stream

Parameters ramp-up function

Mass flow

Mass

Number of discretization layers

Pressure

Heat

Heat flow rate

Temperature

Time

Logarithmic mean temperature for stream i

Volume

Electric power

Levelized cost of capital investment, and

operation and maintenance
[DKK]

$[\mathrm{DKK} / \mathrm{J}]$

$[\mathrm{DKK} / \mathrm{s}]$

$[\mathrm{J} /(\mathrm{kg} * \mathrm{~K})$

[J]

[J/kg]

[W]

[-]

$[\mathrm{kg} / \mathrm{s}]$

[kg]

[-]

[bar]

[J]

[W]

[K]

[s]

[K]

$\left[\mathrm{m}^{3}\right]$

[W]

$[\mathrm{DKK} / \mathrm{s}]$

\section{Greek symbols}

$\frac{\epsilon}{\rho}$

Exergy efficiency

$[-]$

Mean water density

$\left[\mathrm{kg} / \mathrm{m}^{3}\right]$

\section{Subscripts}

0

Reference state

capacity

cold

Per installed capacity

con

Related to cold control volume of the tank

D

Condenser

Destruction 


$\begin{array}{ll}\text { el } & \text { Electricity } \\ \text { eva } & \text { Evaporator } \\ \text { ex } & \text { Per unit of exergy } \\ F & \text { Fuel } \\ \text { flex } & \text { Flexible operation } \\ \text { heat } & \text { Heat supply into DH grid } \\ \text { hot } & \text { Related to hot control volume of the tank } \\ \text { HP } & \text { Heat pump } \\ i & \text { Material stream indicator } \\ \text { in } & \text { Inlet } \\ \text { installed } & \text { Installed capacity } \\ j & \text { Heat flow indicator } \\ k & \text { Component indicator } \\ L & \text { Loss } \\ I & \text { Electricity flow index } \\ m a x & \text { Maximum capacity } \\ m i n & \text { Minimum capacity } \\ n & \text { Discretization layer indicator } \\ \text { nonflex } & \text { Non-flexible operation } \\ \text { out } & \text { Outlet } \\ P & \text { Product } \\ \text { reg } & \text { Regulation energy } \\ \text { season } & \text { Seasonal } \\ \text { ss } & \text { Steady state } \\ \text { storage } & \text { Stratified storage tank } \\ \text { system } & \text { Conversion system } \\ \text { tot } & \text { Yearly mean value } \\ & \end{array}$


482

483

484

485

486

487

488

489

490

491

492

493

494

495

496

497

498

499

500

501

502

503

504

505

506

507

508

509

510

511

512

513

514

515

516

517

518

\section{References}

[1] Lund H, Mathiesen BV. Energy system analysis of 100\% renewable energy systems - The case of Denmark in years 2030 and 2050. Energy 2009;34:524-31. doi:10.1016/j.energy.2008.04.003.

[2] Mathiesen BV, Lund H, Connolly D, Wenzel H, Østergaard PA, Möller B, et al. Smart Energy Systems for coherent $100 \%$ renewable energy and transport solutions. Appl Energy 2015;145:139-54. doi:10.1016/j.apenergy.2015.01.075.

[3] Lund H, Werner S, Wiltshire R, Svendsen S, Thorsen JE, Hvelplund F, et al. 4th Generation District Heating (4GDH): Integrating smart thermal grids into future sustainable energy systems. Energy 2014;68:1-11. doi:10.1016/j.energy.2014.02.089.

[4] Mathiesen BV, Lund $\mathrm{H}$. Comparative analyses of seven technologies to facilitate the integration of fluctuating renewable energy sources. Renew Power Gener IET 2008;3:190-204. doi:10.1049/ietrpg.

[5] David A, Mathiesen BV, Averfalk H, Werner S, Lund H. Heat Roadmap Europe: Large-Scale Electric Heat Pumps in District Heating Systems. Energies 2017;10:578. doi:10.3390/en10040578.

[6] Holttinen H, Cutululis NA, Gubina A, Keane A, Van Hulle F. Ancillary services: technical specifications, system needs and costs. Deliverable D 2.2. 2012.

[7] Carmo C, Detlefsen N, Nielsen M. Smart Grid enabled heat pumps: An empirical platform for investigating how residential heat pumps can support largescale integration of intermittent renewables. Energy Procedia 2014;61:1695-8. doi:10.1016/j.egypro.2014.12.194.

[8] Stinner S, Schlösser T, Huchtemann K, Müller D, Monti A. Primary energy evaluation of heat pumps considering dynamic boundary conditions in the energy system. Energy 2017;138:60-78. doi:10.1016/j.energy.2017.07.029.

[9] Patteeuw D, Reynders G, Bruninx K, Protopapadaki C, Delarue E, D'haeseleer W, et al. CO2abatement cost of residential heat pumps with active demand response: Demand- and supplyside effects. Appl Energy 2015;156:490-501. doi:10.1016/j.apenergy.2015.07.038.

[10] Ulbig A, Andersson G. Analyzing operational flexibility of electric power systems. Int J Electr Power Energy Syst 2015;72:155-64. doi:10.1016/j.ijepes.2015.02.028.

[11] Robbi S. LowEx-Fernwärme - Vergleichende Bewertung von Maßnahmen für eine effiziente, multifunktionale Fernwärmeversorgung (Doctoral thesis). Technische Universität Dresden, 2013.

[12] Schlachtberger DP, Becker S, Schramm S, Greiner M. Backup flexibility classes in emerging largescale renewable electricity systems. Energy Convers Manag 2016;125:336-46.

doi:10.1016/j.enconman.2016.04.020.

[13] Makarov Y V., Loutan C, Ma J, Mello P de. Operational impacts of wind generation on California power systems. IEEE Trans POWER Syst 2009;24, No. 2:1039-50.

doi:10.1109/NOMS.2002.1015622.

[14] Eid C, Codani P, Perez Y, Reneses J, Hakvoort R. Managing electric flexibility from Distributed Energy Resources: A review of incentives for market design. Renew Sustain Energy Rev 2016;64:237-47. doi:10.1016/j.rser.2016.06.008. 
[15] Blarke MB, Lund $\mathrm{H}$. The effectiveness of storage and relocation options in renewable energy systems. Renew Energy 2008;33:1499-507. doi:10.1016/j.renene.2007.09.001.

[16] Meibom P, Kiviluoma J, Barth R, Brand H, Weber C, Larsen H V. Value of electric heat boilers and heat pumps for wind power integration. Wind Energy 2007;10:321-37. doi:10.1002/we.224.

[17] Bejan A, Tsatsaronis G, Moran M. Thermal design and optimization. John Wiley \& Sons, Inc.; 1996.

[18] Sayadi S, Tsatsaronis G, Morosuk T. A New Approach for Applying Dynamic Exergy Analysis and Exergoeconomics to a Building Envelope 2016:1-17.

[19] Sangi R, Martín PM, Müller D. Thermoeconomic analysis of a building heating system. Energy 2016;111:351-63. doi:10.1016/j.energy.2016.05.112.

[20] Modelica Association. Modelica and the Modelica Standard Library 2017. http://www.modelica.org (accessed October 31, 2017).

[21] Dassault Systèmes. Dymola Systems Engineering 2017. https://www.3ds.com/productsservices/catia/products/dymola/ (accessed October 31, 2017).

[22] TLK Thermo GmbH \& IfT. TIL 3.4 - Model library for thermal components and systems 2017.

[23] Grundfos. Product data SP 46-4 2017. https://product-selection.grundfos.com/productdetail.catalogue.product families.html?from_suid=151022228811006388052718785822\&pumpsystemid=280760607\&qci d=271031787 (accessed July 4, 2017).

[24] Grundfos. Product data NB 32 - 200/206 2017. https://product-selection.grundfos.com/productdetail.catalogue.product families.html?from_suid=1510222503906014344929798807637\&pumpsystemid=290981485\&qc id=293056119 (accessed October 30, 2017).

[25] HOFOR. Heat demand data for 3 cruise ship terminal buildings and a warehouse. Copenhagen: 2012.

[26] Jensen JK, Ommen T, Markussen WB, Elmegaard B. Design of serially connected district heating heat pumps utilising a geothermal heat source. Energy 2017. doi:10.1016/j.energy.2017.03.164.

[27] Pfeil HV. Intelligent Capacity Control Potential for System Efficiency Improvements \& Energy Savings. ICR 2015, Yokohama, Japan: 2015, p. ID:16. doi:10.18462/iir.icr.2015.0016.

[28] Energinet.dk. Energinet.dk - Markedsdata 2012. http://www.energinet.dk (accessed July 10, 2017).

[29] Rothuizen E, Markussen W, Elmegaard B, Madsen C, Olesen MF, Sølvsten M. High Efficient Heat Pump System Using Storage Tanks To Increase Cop By Means of the Isec Concept ( Part I , Thermal Storage System ). Proc 24th IIR Int Congr Refrig 2015:1-8.

[30] Lazzaretto A, Tsatsaronis G. SPECO: A systematic and general methodology for calculating efficiencies and costs in thermal systems. Energy 2006;31:1257-89. doi:10.1016/j.energy.2005.03.011.

[31] Rosen MA, Dincer I. Thermal energy storage systems and applications. 2nd ed. Ontario, Canada: 
John Wiley \& Sons, Inc.; 2011.

558

559

560

561

562

563

564

565

566

567

568

569

570

571

572

573

574

575

[32] Center for Klima og Energiøkonomi. Forudsætninger for samfunds økonomiske analyser på energiområdet 2016;Version 3.

https://ens.dk/sites/ens.dk/files/Analyser/samfundsoekonomiske_beregningsforudsaetninger_2 016_v3.pdf.

[33] Energinet.dk. Marketsdata 2017. www.energinet.dk (accessed July 10, 2017).

[34] Energinet.dk. Technology Data for Energy Plants 2016. www.ens.dk (accessed October 12, 2017).

[35] Energinet.dk. Technology Data for Energy Plants 2012. https://ens.dk/sites/ens.dk/files/Analyser/technologydata_for_energy_plants__may_2012._updated_2015.pdf (accessed October 12, 2017).

[36] Baeten B, Rogiers F, Helsen L. Reduction of heat pump induced peak electricity use and required generation capacity through thermal energy storage and demand response. Appl Energy 2017:184-95. doi:10.1016/j.apenergy.2017.03.055.

[37] Arteconi A, Patteeuw D, Bruninx K, Delarue E, D 'haeseleer W, Helsen L. Active demand response with electric heating systems: Impact of market penetration. Appl Energy 2016;177:636-48. doi:10.1016/j.apenergy.2016.05.146.

[38] Hedegaard K. Wind power integration with heat pumps, heat storages, and electric vehicles Energy systems analysis and modelling (PhD thesis) 2013. 
Highlights - Dynamic exergoeconomic analysis of a heat pump system used for ancillary services in an integrated energy system

- Dynamic exergoeconomic analysis

- Cost allocation method for regulation power and heat provided by the heat pump

- Large scale heat pump providing manual reserve regulation

- Exergy destruction increase for flexible operation due to storage and reheating 